\title{
Detecting Spatiotemporal Features and Rationalities of Urban Expansions within the Guangdong-Hong Kong-Macau Greater Bay Area of China from 1987 to 2017 Using Time-Series Landsat Images and Socioeconomic Data
}

\author{
Chao Yang ${ }^{1,2}{ }^{\oplus}$, Qingquan Li ${ }^{1, *}$, Tianhong Zhao ${ }^{1}{ }^{\oplus}$, Huizeng Liu ${ }^{1}\left(\mathbb{D}\right.$, Wenxiu Gao ${ }^{3}$, \\ Tiezhu Shi ${ }^{1}$, Minglei Guan ${ }^{1,2}$ and Guofeng $\mathrm{Wu}^{1,4}$ \\ 1 Key Laboratory for Geo-Environmental Monitoring of Coastal Zone of the Ministry of Natural Resources \& \\ Guangdong Key Laboratory of Urban Informatics \& Shenzhen Key Laboratory of Spatial Smart Sensing and \\ Services, Shenzhen University, Shenzhen 518060, China; yangchao2017@email.szu.edu.cn (C.Y.); \\ zhaotianhong2016@email.szu.edu.cn (T.Z.); HuizengLiu@life.hkbu.edu.hk (H.L.); \\ tiezhushi@szu.edu.cn (T.S.); guanminglei@szu.edu.cn (M.G.); guofeng.wu@szu.edu.cn (G.W.) \\ 2 College of Information Engineering, Shenzhen University, Shenzhen 518060, China \\ 3 School of Architecture and Urban Planning, Shenzhen University, Shenzhen 518060, China; \\ wxgao@szu.edu.cn \\ 4 College of Life Sciences and Oceanography, Shenzhen University, Shenzhen 518060, China \\ * Correspondence: liqq@szu.edu.cn; Tel.: +86-10-6485-5094
}

Received: 2 September 2019; Accepted: 20 September 2019; Published: 23 September 2019; Corrected: 22 August 2022

\begin{abstract}
The Guangdong-Hong Kong-Macau Greater Bay Area (GBA) of China is one of the major bay areas in the world. However, the spatiotemporal characteristics and rationalities of urban expansions within this region over a relatively long period of time are not well-understood. This study explored the spatiotemporal evolution of 11 cities within the GBA in 1987-2017 by integrating remote sensing, landscape analysis, and geographic information system (GIS) techniques, and further evaluated the rationalities of their expansion using the urban area population elastic coefficient (UPEC) and the urban area gross domestic product (GDP) elastic coefficient (UGEC). The results showed the following: (1) Guangzhou, Shenzhen, Foshan, Dongguan, Zhongshan, and Zhuhai experienced unprecedented urbanization compared with the other cities, and from 1987 to 2017, their urban areas expanded by 10.12, 11.48, 14.21, 24.90, 37.07, and 30.15 times, respectively; (2) several expansion patterns were observed in the 11 cities, including a mononuclear polygon radiation pattern (Guangzhou and Foshan), a double-nucleated polygon pattern (Macau and Zhongshan), and a multi-nuclear urbanization pattern (Shenzhen, Hong Kong, Dongguan, Jiangmen, Huizhou, Zhaoqing, and Zhuhai); (3) with regard to the proportion of area, the edge-expansion and outlying growth types were the predominant types for all 11 cities, and the infilling growth type was the one of the important types during 2007-2017 for Shenzhen, Hong Kong, Dongguan, Zhongshan, and Foshan; (4) the expansion of most cities took on an urban-to-rural landscape gradient, especially for Guangzhou, Shenzhen, Foshan, Zhongshan, Dongguan, and Zhuhai; and (5) the rationalities of expansion in several time periods were rational for Guangzhou (1997-2007), Hong Kong (2007-2017), Foshan (1987-2007), Huizhou (1987-1997), and Dongguan (1997-2007), and the rationalities of expansion in the other cities and time periods were found to be irrational. These findings may help policy- and decision-makers to maintain the sustainable development of the Guangdong-Hong Kong-Macau Greater Bay Area.
\end{abstract}

Keywords: urbanization; spatiotemporal evolution; rationality; landscape analysis; remote sensing 


\section{Introduction}

Urban growth has reached an unparalleled speed over the past few decades. The urban population increased to $54 \%$ of the world's population in 2014 from $30 \%$ in 1950 [1], and it is projected to reach $66 \%$ of the world's population in 2050 [2]. Urban growth is faster in Africa and Asia compared with other regions in the world, and it is predicted that the urban population will increase to $56 \%$ and $64 \%$ by 2050, respectively, in these two regions [2]. Continuous urbanization will cause 2.5 billion people to be moved to urban regions by 2050 , and nearly $90 \%$ of the increased urban population will be concentrated in Asia and Africa [3]. As a drastic change in land cover/use, urban expansion also affects ecosystems locally and globally [4-6]. Its quantitative characterization can be used in urban planning, urban management, and urban area prediction, and help us to understand and assess the ecologic influence of urban expansion and analyze the driving forces [7-9].

Urbanization improves the residents' living standards because urban development can improve living conditions and provide more public services, such as transportation, parks, and shopping plazas [10]. However, urbanization also causes many environment problems, such as global warming, water pollution, air pollution, greenhouse gas emissions, enhanced urban heat island effects, and industrial wastes [2,11-13]. In addition, ecological degradations resulting from urban expansion, such as the loss of biodiversity and climate changes, can also exert an influence on local and global ecosystem services, which will eventually affect the ability to sustain urban development $[5,6]$. It is worth noting that human activities have greatly promoted the fragmentation of urban landscapes [14]. Therefore, in order to promote sustainable regional development, there is an urgent need to understand the spatio-temporal characteristics of urban expansion.

China has undergone a rapid urban expansion since the reform and opening up policy was introduced in 1978. The urban area in China has expanded six times and the number of cities increased to 657 in 2011 from 193 in 1978 [15,16]. Meanwhile, socioeconomic development and urban expansion have resulted in significant landscape changes [17]. For examples, urban expansion patterns in some cities have shifted from outlying expansion to edge-expansion and infilling growth [18,19]; meanwhile, edge-expansion growth and extensive outlying expansion indicate that the suburbanizing process is underway. Along with the dramatic growth in the population and economy [20], environmental problems caused by the urban sprawl have occurred in many Chinese cities [21-23]. Thus, accurately evaluating the rationality of urban expansion is paramount importance to our understanding of the urbanization process and its ecological effects [24].

To obtain information on urban expansion, two kinds of data are frequently applied: socioeconomic statistical data from public institutions [20] and optical remote sensing images. The socioeconomic statistical data are insufficient to reveal the spatial features of urban expansion, owing to lacking spatial scalability and extensibility. By contrast, remote sensing images can be applied to reveal urban expansion owing to their ability to effectively describe spatiotemporal patterns [25-29]. Among the various sources of remotely sensed data, geographic coverage and temporal resolution are limited in high-resolution remote sensing images, and traditional low-resolution remote sensing images cannot comprehensively reflect the details of changes that have happened to urban expansion as they are limited by their spatial resolutions [30]. The Landsat multispectral scanner (MSS), thematic mapper (TM), enhanced thematic mapper plus (ETM+), and operational land imager (OLI) provide images over a four-decade time period with relatively wide geographic coverage [31-33], and they hold the potential to map urban areas at a moderate scale [34,35]. Moreover, few studies have combined socioeconomic data with time-series Landsat images to understand the process of urban expansion in the long term [36,37].

Remote sensing (RS), coupled with a geographic information system (GIS), has been successfully applied in urban expansion studies [38-40]. Moreover, landscape ecology approaches, such as landscape metrics [41,42], patch dynamics [43], and gradient analyses [44,45], may be conducive to characterizing the dynamics of urban expansion and describing the details and structures of spatiotemporal patterns at multiple scales [46-49]. Recently, analyses of temporal variation and the scale effect were carried out 
by applying landscape indices to multi-scale or multi-temporal datasets [50-53]. By combining remote sensing images and GIS techniques with landscape ecology approaches, studies have quantified the urban expansion in different cities and urban agglomerations all over the globe [54-56]. As a "proxy", the urban area population elastic coefficient (UPEC) and the urban area gross domestic product (GDP) elastic coefficient (UGEC) are two effective indices to assess the rationality of urban expansion [57]. The UPEC and UGEC are defined as the ratio of urban area growth rate to population growth rate and urban area growth rate to gross domestic product (GDP) growth rate, respectively. They can be applied to measure how urban population growth rate and urban expansion correlate with each other, as well as to study the relationship between GDP growth rate and urban expansion (i.e., the efficiency of urban land use) $[57,58]$, and they have also been successfully used to evaluate the rationality of urban expansion in China $[57,59,60]$.

The Guangdong-Hong Kong-Macau Greater Bay Area (GBA) of China is the largest morphologically contiguous urban agglomeration in the world [61]. The GBA has been undergoing a remarkable urban expansion over the past several decades [56]. The population of the GBA accounts for only $5 \%$ of China's total population; however, in 2017, it created approximately $11 \%$ of China's total GDP. To promote sustainable regional development, the Chinese government published the "Development Plan for the Guangdong-Hong Kong-Macao Greater Bay Area" in 2019. According to this plan, the GBA should not only become a world-class urban agglomeration, and an area for the demonstration of deep cooperation between the mainland and Hong Kong and Macao, but also create a good-quality life circle that is livable, occupational, and promotes tourism. Some studies have analyzed the spatiotemporal patterns of urban expansion in an individual city or urban agglomeration [26,38,62-65]; however, few studies have focused on systematic cross-city comparisons within an urban agglomeration over the past four decades $[39,66,67]$, particularly in the GBA. Moreover, the details of the spatiotemporal characteristics of urban expansions within the GBA are quite important to the local government's urban planning, and the rationality of urban expansion within this region remains underexplored.

Therefore, there is an urgent need to investigate and compare the urban expansion characteristics and their rationalities in the cities within the GBA in different political systems and at different development stages. The present study aimed to reveal the spatiotemporal evolution of the urban expansion of 11 cities within the GBA, and further evaluated the rationalities of their expansion using time-series Landsat images and socioeconomic data from 1987 to 2017 for the following purposes: (1) to effectively map the spatiotemporal distribution of urban areas; (2) to quantify urban expansions; (3) to compare the temporal changes in landscape metrics and spatially explicit urban growth patterns; and (4) to assess the rationality between urban expansion and population and GDP growth. The conclusions that are drawn in this study may help us to sustainably develop this bay area, and our results may be helpful to urban planning.

\section{Data and Methods}

\subsection{Study Area}

The GBA $\left(21^{\circ} 32^{\prime}-24^{\circ} 26^{\prime} \mathrm{N}, 111^{\circ} 20^{\prime}-115^{\circ} 24^{\prime} \mathrm{E}\right)$ is located in the south of China, and it contains 11 cities (i.e., Guangzhou, Shenzhen, Hong Kong, Macau, Foshan, Jiangmen, Zhongshan, Huizhou, Dongguan, Zhaoqing, and Zhuhai). Among these cities, the terrains of Zhaoqing, Huizhou, and Hong Kong, southeast of Shenzhen and northeast of Guangzhou, are obviously undulating and mountainous (Figure 1). The highest and lowest elevations of the GBA are -138 and $1589 \mathrm{~m}$, respectively. The GBA has a population of more than 66 million and a total area of approximately 56,000 square kilometers. This bay area has a large number of financial services, educational resources, manufacturing industries, high-tech industries, tourism industries, and cultural industries. Among the numerous industrial structures, Hong Kong's economic growth is dominated by financial services; Dongguan, Zhongshan, Zhuhai, Jiangmen Huizhou, and Zhaoqing mainly depend on manufacturing industries; Shenzhen relies on high-tech industries; Macau focuses on tourism and service industries; and Guangzhou's 
industrial structure is more balanced compared with other cities. The GBA is also the starting point of the Maritime Silk Road and China's gateway to the world.

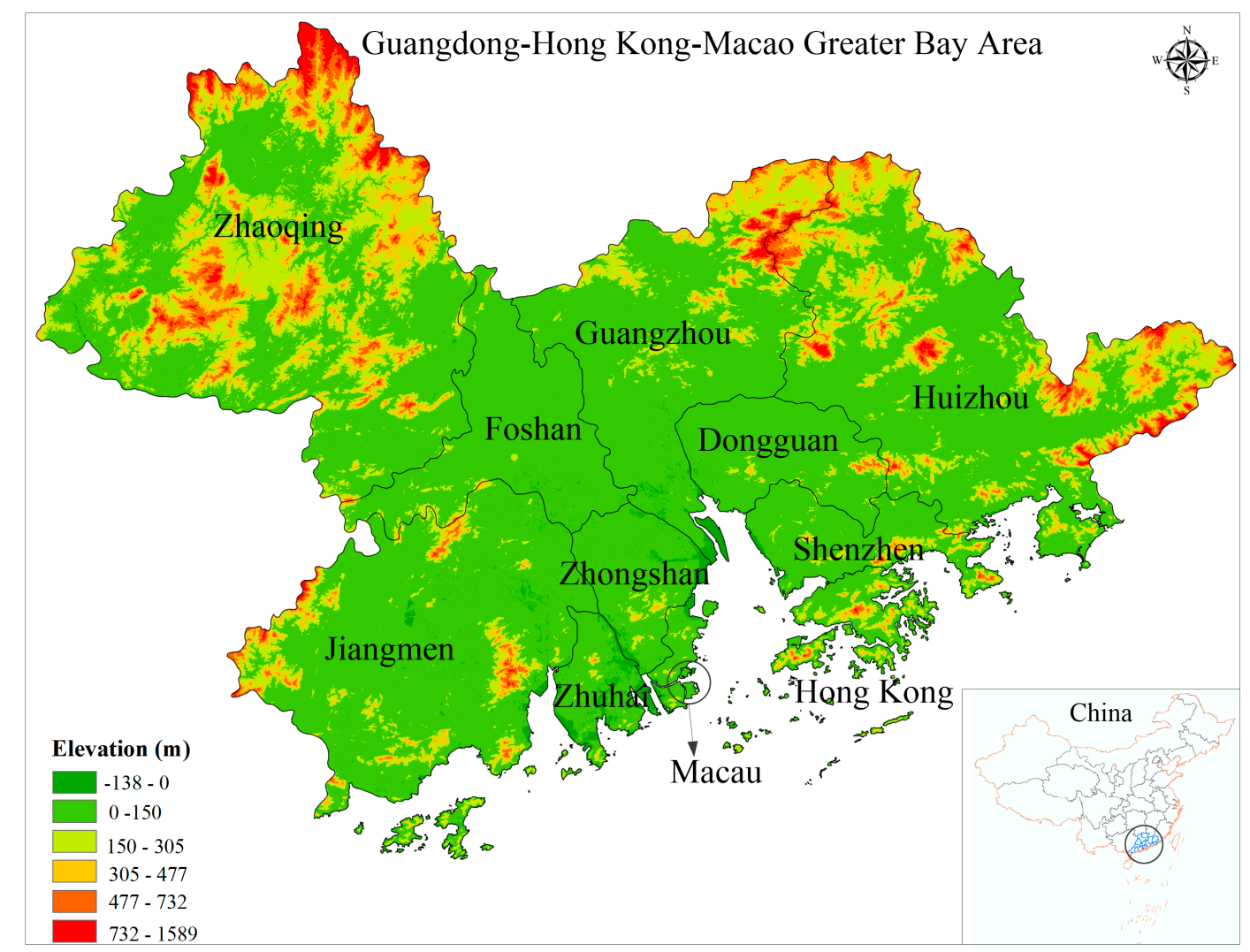

Figure 1. The location of the Guangdong-Hong Kong-Macau Greater Bay Area (GBA) of China.

\subsection{Data Sources and Data Processing}

Thirty-two Landsat TM and OLI images (Table 1), captured during 1987, 1997, 2007, and 2017, were downloaded from the United States Geological Survey (USGS)'s Global Visualization Viewer (GloVis, https://glovis.usgs.gov/). These images have six (for TM) or eight (for OLI) spectral bands at visible and shortwave wavelengths with a $30 \times 30 \mathrm{~m}$ spatial resolution. The ENVI 5.2 software (https://www.harrisgeospatial.com) was applied to process the downloaded Landsat TM/OLI images in advance, including subset and FLAASH atmospheric correction and a combination of band, image mosaic, and clipping. The urban areas of the 11 cities were obtained through a land cover classification strategy with the object-oriented support vector machine (O-SVM) classifier that was employed by Yang et al. [56] (Figure 2). The land cover types included urban land, croplands/grasslands, forestland, water, and cultivated/exposed land. The O-SVM method integrates a novel bi-level scale-sets model (BSM) [68] and a support vector machine (SVM) [69,70], and it is capable of combining the BSM's highly efficient processing of large-scale images [68] with SVM's highly accurate application of small training sets [71]. The O-SVM method is able to effectively classify land cover types, particularly in large- or moderate-scale urban area extraction [56]. The O-SVM method that was used in this study was applied by combining the Scale-Sets-Image-Analysis-Toolkit (https://github.com/zwhoo/Scale-SetsImage-Analysis-Toolkit) and SVM methods. The parameters of the O-SVM were obtained through careful tests, and the object segmentation scales were set to 30 (TM images) and 45 (OLI images), respectively. Four kinds of characteristics (i.e., texture, spectral, spatial, and indices) for each object were applied in the classification [56]. The SVM classifier was constructed using a radial basis function $(\mathrm{RBF})$. The Gamma coefficient of the SVM classifier was set to $1 / \mathrm{n}$ (where $\mathrm{n}$ refers to the number of bands of the Landsat TM/OLI images; $n$ equals 6 for TM and 8 for OLI), and the penalty cost took a 
value of 100, suggesting a higher extraction accuracy [72]. The classification accuracy was confirmed using a confusion matrix with indexes of basic precision, including user's accuracy (UA), producer's accuracy (PA), overall accuracy (OA), and Kappa coefficient [73-75]. In total, 837 validation samples of land cover types, covering the study areas evenly from 1987 to 2017, were chosen at random from Google Earth Pro ${ }^{\circledR} ; 321$ samples were chosen for the year 1987, 155 for 1997, 184 for 2007, and 177 for 2017. All accuracy metrics of the classification using the validation samples were greater than 0.80 , and most were greater than 0.85 (Table 2), which fulfilled the accuracy requirement for land cover change evaluation [76], considering that a Kappa coefficient of greater than 0.80 is deemed as 'high accuracy' [77]. As our study was focused on analyses of urban expansion in the 11 cities, only the urban land type was retained in the subsequent analyses, and other land cover types were merged into a single "non-urban area" land cover type. Table 3 contains information on the population and gross domestic product (GDP) of the 11 cities within the GBA.

Table 1. Information on the images that were applied in the study. OLI, operational land imager; TM, thematic mapper.

\begin{tabular}{cccccccccccc}
\hline \multicolumn{2}{c}{ 1987 (Landsat TM) } & \multicolumn{3}{c}{ 1997 (Landsat TM) } & \multicolumn{2}{c}{ 2007 (Landsat TM) } & \multicolumn{2}{c}{ 2017 (Landsat OLI) } \\
\hline $\begin{array}{c}\text { Path/ } \\
\text { row }\end{array}$ & Date & $\begin{array}{c}\text { Cloud } \\
(\%)\end{array}$ & $\begin{array}{c}\text { Path/ } \\
\text { row }\end{array}$ & Date & $\begin{array}{c}\text { Cloud } \\
(\%)\end{array}$ & $\begin{array}{c}\text { Path/ } \\
\text { row }\end{array}$ & Date & $\begin{array}{c}\text { Cloud } \\
(\%)\end{array}$ & $\begin{array}{c}\text { Path/ } \\
\text { row }\end{array}$ & $\begin{array}{c}\text { Date } \\
\text { Dloud } \\
(\%)\end{array}$ \\
\hline $122 / 44$ & 1987.12 .8 & 0.32 & $122 / 44$ & 1997.8 .29 & 1.00 & $122 / 44$ & 2007.1 .29 & 0.02 & $122 / 44$ & 2017.10 .23 & 0.05 \\
$121 / 44$ & 1987.8 .11 & 0.02 & $121 / 44$ & 1997.1 .10 & 0.00 & $121 / 44$ & 2006.12 .21 & 0.11 & $121 / 44$ & 2017.11 .1 & 0.03 \\
$122 / 45$ & 1987.2 .7 & 4.00 & $122 / 45$ & 1997.8 .29 & 0.05 & $122 / 45$ & 2007.7 .24 & 4.27 & $122 / 45$ & 2017.8 .20 & 7.89 \\
$121 / 45$ & 1987.8 .11 & 0.00 & $121 / 45$ & 1996.8 .19 & 2.00 & $121 / 45$ & 2007.1 .30 & 0.53 & $121 / 45$ & 2017.8 .29 & 3.51 \\
$122 / 43$ & 1987.12 .8 & 0.03 & $122 / 43$ & 1997.11 .1 & 4.00 & $122 / 43$ & 2007.4 .19 & 1.00 & $122 / 43$ & 2017.12 .16 & 0.70 \\
$123 / 44$ & 1987.9 .10 & 0.00 & $123 / 44$ & 1997.10 .23 & 4.00 & $123 / 44$ & 2006.12 .19 & 0.05 & $123 / 44$ & 2017.10 .30 & 1.00 \\
$123 / 45$ & 1987.9 .10 & 0.55 & $123 / 45$ & 1997.11 .8 & 3.00 & $123 / 45$ & 2007.7 .15 & 0.00 & $123 / 45$ & 2017.9 .12 \\
$123 / 43$ & 1987.9 .10 & 0.00 & $123 / 43$ & 1996.12 .23 & 0.00 & $123 / 43$ & 2007.2 .5 & 0.47 & $123 / 43$ & 2017.10 .30 & 2.05 \\
\hline
\end{tabular}

Table 2. A summary of the assessment of the urban area classification's accuracy. UA, user's accuracy; PA, producer's accuracy; OA, overall accuracy.

\begin{tabular}{ccccc}
\hline Date & OA (\%) & Kappa & PA (\%) & UA (\%) \\
\hline 1987 & 88.16 & 0.84 & 87.50 & 80.00 \\
1997 & 90.32 & 0.88 & 93.54 & 93.55 \\
2007 & 90.22 & 0.88 & 87.80 & 92.31 \\
2017 & 90.39 & 0.87 & 90.70 & 97.50 \\
Average & 89.77 & 0.87 & 89.89 & 90.84 \\
\hline
\end{tabular}

Table 3. Information on the gross domestic product (GDP) and population of the 11 cities within the Greater Bay Area (GBA).

\begin{tabular}{ccccccccc}
\hline \multirow{2}{*}{ Periods } & \multicolumn{2}{c}{1987} & \multicolumn{2}{c}{ 1997 } & \multicolumn{2}{c}{$\mathbf{2 0 0 7}$} & \multicolumn{2}{c}{$\mathbf{2 0 1 7}$} \\
\cline { 2 - 8 } & Population & GDP & Population & GDP & Population & GDP & Population & GDP \\
\hline Guangzhou & 576.91 & 173.21 & 666.49 & 1678.12 & 949.68 & 7140.32 & 1449.84 & $19,547.44$ \\
Shenzhen & 105.44 & 55.90 & 527.75 & 1297.42 & 912.37 & 6801.57 & 1190.84 & $19,492.60$ \\
Hong Kong & 558.05 & 1916.81 & 650.21 & 6363.52 & 685.71 & $13,139.29$ & 733.66 & $21,771.35$ \\
Macau & 43.43 & 139.86 & 42.21 & 452.51 & 53.18 & 1140.58 & 65.31 & 3128.09 \\
Foshan & 145.93 & 69.12 & 367.46 & 724.6 & 629.67 & 3660.18 & 765.67 & 9549.60 \\
Huizhou & 231.25 & 22.41 & 291.32 & 318.90 & 402.86 & 1117.91 & 475.55 & 3412.17 \\
Jiangmen & 348.93 & 60.45 & 380.60 & 424.58 & 421.32 & 1097.26 & 456.17 & 2690.25 \\
Zhongshan & 124.92 & 27.58 & 195.2 & 234.72 & 268.68 & 1268.04 & 326.0 & 3450.31 \\
Dongguan & 175.62 & 39.29 & 336.45 & 448.60 & 656.07 & 3160.05 & 749.66 & 7582.12 \\
Zhaoqing & 320.10 & 56.62 & 331.93 & 211.85 & 378.31 & 619.69 & 408.46 & 2200.61 \\
Zhuhai & 52.62 & 15.95 & 101.46 & 234.04 & 147.44 & 894.81 & 176.54 & 2564.73 \\
\hline
\end{tabular}

Note: All statistical data were obtained from a local statistics yearbook. Data from 2017 for Guangzhou, Shenzhen, Huizhou, and Hong Kong were not available, and they were replaced by those from 2016. Population unit: 10,000; GDP unit: 100 million RMB (approximately speaking, one RMB is equivalent to 0.16 U.S. Dollars). 


\subsection{Urban Expansion Pattern}

\subsubsection{Quantification of Urban Expansion}

To quantify an urban expansion's magnitude, three commonly used indexes were adopted in this study: annual growth rate (AGR, \%) annual increase (AI, $\mathrm{km}^{2} / \mathrm{year}$,) and expansion rate (ER, \%) $[56,78,79]$ (Equations (1)-(3)). ER and AI were used to compare the urban expansion over a period of years for a single city through the direct measurement of the annual increase in the extent of the urban area and the rate of urban area expansion, respectively, while AGR was used to compare the various cities' urban expansions in a certain year by means of eliminating the impact of a city's size.

$$
\begin{gathered}
E R=\frac{U_{\text {end }}-U_{\text {start }}}{n \times U_{\text {start }}} \times 100 \% \\
A I=\frac{U_{\text {end }}-U_{\text {start }}}{n} \\
A G R=\left[\left(\frac{U_{\text {end }}}{U_{\text {start }}}\right)^{1 / n}-1\right] \times 100 \%
\end{gathered}
$$

where $n$ denotes the number of years and $U_{\text {start }}$ and $U_{\text {end }}$ refer to the extent of the urban area at end and start dates, respectively.

\subsubsection{Classification of Urban Expansion Type}

Three spatial types of urban growth—infilling, outlying, and edge expansion $[80,81]$ —were applied in this study to describe urban expansion, and they were defined using the landscape expansion index (LEI) [82] (Equation (4)). The LEI is defined using a buffer analysis. The buffer is the zone with specified distances around a target geographical feature. The analysis can be applied to determine which patches occur either within or outside the defined buffer zone. A set of rules proposed by Liu et al. [82] was applied to describe the three urban growth types: (a) infilling growth type refers to newly grown urban patches where the buffer zones indicate that the direct surroundings are mostly already occupied by the old urban patches (Figure 2a); (b) edge-expansion growth type means the buffer zone is occupied by the old urban patches and non-urban patches, and the region occupied by non-urban areas is more than $50 \%$ (Figure $2 \mathrm{~b}$ ); and (c) outlying growth type refers to the case in which buffer zones are completely occupied by non-urban areas (Figure 2c).

$$
L E I=\frac{S_{o}}{S_{o}+S_{v}} \times 100
$$

where $S_{o}$ is the intersection between the buffer zone and occupied category of the newly grown patch, $S_{v}$ refers to the vacant category's intersection with the buffer zone, and the LEI takes a value between 0 and 100. The urban expansion type was assumed to be infilling if the LEI was over 50, the urban expansion type was assumed to be outlying if the LEI was between 0 and 50 , and the urban expansion type was assumed to be edge-expansion if the LEI was equal to 0 . A smaller value of buffer distance denotes an LEI value that is much more stable, and, in the present study, we set the buffer distance to $1 \mathrm{~m}[82,83]$. 


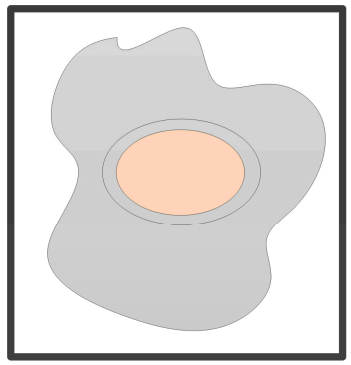

(a) Infilling

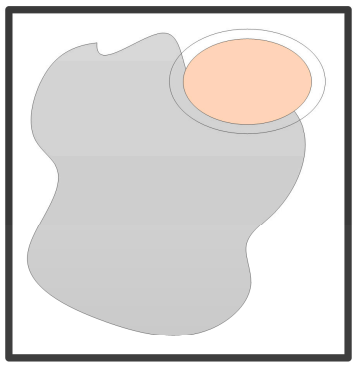

(b) Edge-expansion

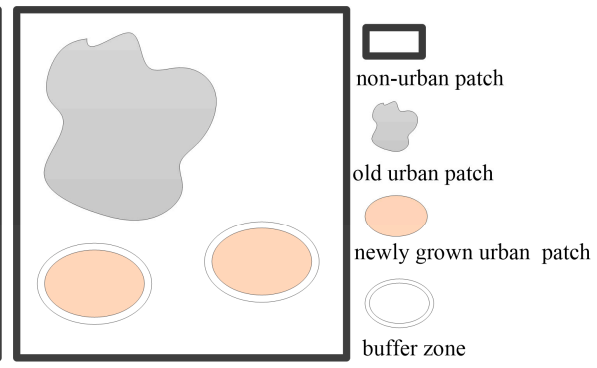

(c) Outlying

Figure 2. The three urban growth types (infilling, outlying, and edge-expansion).

\subsection{Urban Landscape Pattern Analysis}

To characterize the landscape changes and spatial patterns, six class-level landscape metrics were applied: percentage of landscape (PLAND), number of patches (NP), landscape shape index (LSI), largest patch index (LPI), patch density (PD), and fragmentation index (FI) (Table 4) [84,85]. The PLAND is a measure to assess landscape composition and is used to depict the growth of urban area $[86,87]$. NP and PD belong to density metrics that focus on the subdivision aspect of urban aggregation, and they are expected to increase during periods of rapid urban nuclei development, but may decrease if urban areas expand and merge into a continuous urban fabric $[48,56]$. LSI is a shape metric to measure the regularity of urban growth, and a large LSI indicates an irregular the urban shape [87]. LPI is a measure to evaluate if the largest patch is dominating the landscape or if the distribution of large patches is more even, and it was used as one indicator to define the dominance of the urban core $[79,87,88]$. FI represents the degree of fragmentation of urban landscape, which reflects the complexity of urban spatial structure [56]. With the help of eight neighborhood rules, the abovementioned metrics were calculated using the FRAGSTATS 4.2 software (https://www.umass.edu/landeco/research/fragstats/fragstats.html) [86]. Additionally, to investigate the composition of the patches, the percentages of each patch's area and frequency distribution in accordance with eight patch size classes (i.e., $0-0.5,0.5-1,1-5,5-10,10-50,50-100,100-500$, and $>500 \mathrm{~km}^{2}$ ) were generated.

Table 4. The landscape metrics that were applied in the present study.

\begin{tabular}{|c|c|c|c|}
\hline Landscape metric title & Units & Equations & Description \\
\hline $\begin{array}{l}\text { PLAND (percentage of } \\
\text { landscape) }\end{array}$ & $\%$ & $P L A N D=\frac{\sum_{j=1}^{n} a_{i j}}{A}(100)$ & $\begin{array}{l}\text { The proportion of the total } \\
\text { landscape consisting of the } \\
\text { corresponding class }\end{array}$ \\
\hline LPI (largest patch index) & $\%$ & $L P I=\frac{M a x\left(a_{1}, a_{2}, \ldots a_{n}\right)}{A}(100)$ & $\begin{array}{l}\text { The percentage of area that is } \\
\text { occupied by the largest patch of } \\
\text { one patch type }\end{array}$ \\
\hline $\begin{array}{l}\text { LSI (landscape shape } \\
\text { index) }\end{array}$ & Non & $L S I=\frac{0.25 E}{\sqrt{A}}$ & $\begin{array}{l}\text { The total amount of edge within } \\
\text { the landscape and landscape } \\
\text { boundary, which is divided by the } \\
\text { total area and adjusted by a } \\
\text { constant for a square standard }\end{array}$ \\
\hline NP (number of patches) & Number & $N P=\sum_{i=1}^{n} N_{i}$ & $\begin{array}{l}\text { The total number of patches for } \\
\text { each individual class }\end{array}$ \\
\hline PD (patch density) & Number/100 ha & $P D=\frac{N_{i}}{A}(10000)(100)$ & The number of patches per 100 ha \\
\hline FI (fragmentation index) & Number/ha & $F_{i}=\frac{N_{i}}{A_{i}}$ & $\begin{array}{l}\text { The degree of fragmentation of the } \\
\text { corresponding class }\end{array}$ \\
\hline
\end{tabular}

Note: $A$, total area of the landscape; $a_{i j}$, the area of patch $i j ; N_{i}$, the number of patches for class $i ; A_{i}$, the total area of class $i$; $E$, the total length of the patch boundary. 


\subsection{Rationality of Urban Expansion}

The urban area population elastic coefficient (UPEC) and the urban area GDP elastic coefficient (UGEC) [57,58] were used to evaluate the rationality of urban expansion (Equations (5) and (6), respectively):

$$
\begin{gathered}
U P E C=A(i) / \operatorname{Pop}(i) \\
U G E C=A(i) / G(i)
\end{gathered}
$$

where $A(i)$ refers to the urban area's average growth rate in period $i$, and Pop $(i)$ and $G(i)$ denote the growth rate of the population on average and the GDP in period $i$, respectively. Urban population is one of the forces that drive urban land expansion, and a highly linear relationship between population growth and built-up area expansion was observed in China [57]. In theory, the urban area growth rate should be synchronized with the population growth rate (UPEC $=1)$; however, China's urban population density is large and infrastructure is in short supply. In order to meet infrastructure construction needs, the growth rate of the urban area should be slightly higher than the population growth rate (UPEC > 1) [89]. Therefore, when the value of UPEC is closer to 1, the rationality of urban expansion is reasonable. The value of 1.12 is considered to be more reasonable for China's cities (when the urban population increases by $1 \%$, the urban area should increase by $1.12 \%$ [89]; when UPEC < 1.12 , urban land will be in short supply; and when UPEC $>1.12$, the efficiency of urban land use is low) $[58,59,90]$. The value of UGEC is not unified, but the trend of urban expansion and economic change can be quantified through a comparison of multi-period data [58].

\section{Results}

\subsection{Urban Expansion Pattern}

\subsubsection{Urban Expansion Quantification}

The 11 cities in the GBA experienced rapid urbanization in 1987-2017 (Figure 3), particularly Guangzhou, Shenzhen, Foshan, Zhongshan, Dongguan, and Zhuhai. Guangzhou and Foshan expanded from their original urban cores (Figure 3a,e). Except for the expansions from the original urban cores in Macau and Zhongshan, a secondary nuclear rudiment was initially engendered in the south coast for Macau and the north for Zhongshan in 1997, and the expansion of the secondary urban core areas exceeded that of the original urban cores in 2007 (Figure 3d,h). The urban areas of Shenzhen, Hong Kong, Huizhou, Jiangmen, Dongguan, Zhaoqing, and Zhuhai were distributed across the whole of the city, with many growth points and polygons around the urban cores (Figure $3 b, c, f, g, i-k$ ).

Tables 5 and 6 demonstrate the evolution and expansion velocity of the urban area in each of the 11 cities, respectively. From 1987 to 2017, the urban area increased by 10.12, 11.48, 2.23, 3.79, 14.21, 11.61, 14.39, 37.07, 24.90, 12.69, and 30.15 times in Guangzhou, Shenzhen, Hong Kong, Macau, Foshan, Huizhou, Jiangmen, Zhongshan, Dongguan, Zhaoqing, and Zhuhai, respectively (Table 5). The size of the urban area in Guangzhou, Foshan, and Dongguan exceeded $1000 \mathrm{~km}^{2}$; the size of the urban area in Shenzhen, Huizhou, Jiangmen, and Zhongshan increased by more than $500 \mathrm{~km}^{2}$; and the other cities expanded by less than $400 \mathrm{~km}^{2}$ in 2017 (Table 5). The magnitude of the urban expansion was determined using the ER, AI, and AGR in all 11 cities for three neighboring periods from 1987 to 2017 (Table 6). A comparison of these 11 cities shows that the average ER of Shenzhen, Foshan, Huizhou, Zhongshan, Dongguan, Zhaoqing and Zhuhai exceeded 15\%, particularly Dongguan, Zhongshan, and Zhuhai (greater than 20\%). Moreover, Guangzhou, Shenzhen, Foshan and Dongguan, with a relatively large average AI, exceeded $23 \mathrm{~km}^{2}$, and the other cities were less than $20 \mathrm{~km}^{2}$. Regarding the AGR, Foshan, Dongguan, Jiangmen, Zhaoqing, and Zhuhai exceeded the average value of the other cities, and it is worth noting that Hong Kong had the smallest average AGR (2.71\%) (Table 6). 
(a) Guangzhou

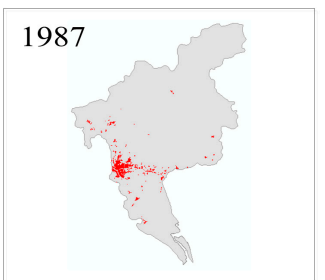

(b) Shenzhen

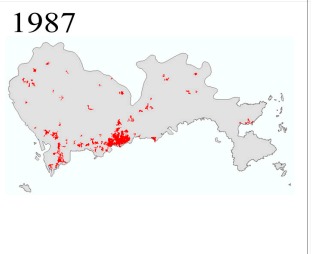

(c) Hong Kong

1987

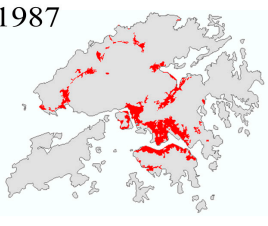

(d) Macao

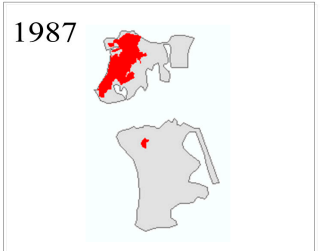

(e) Foshan

1987

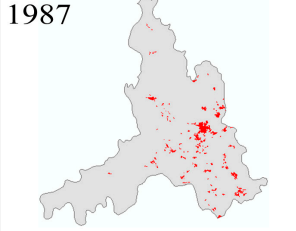

(f) Huizhou

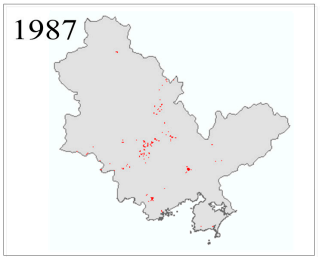

1997

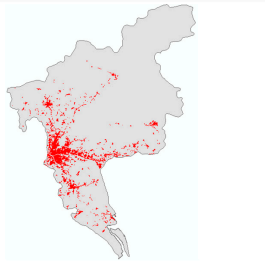

1997
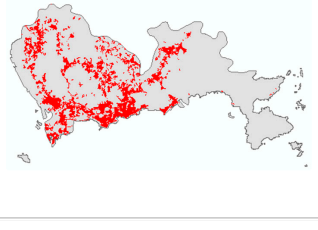

1997

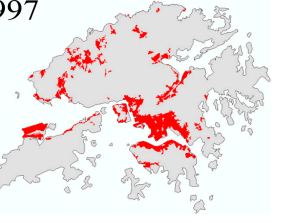

1997

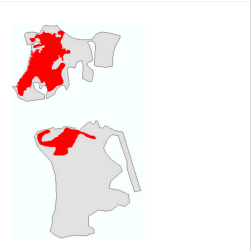

1997

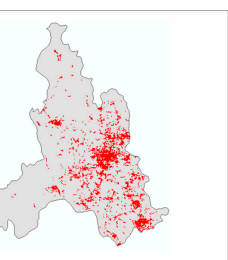

1997

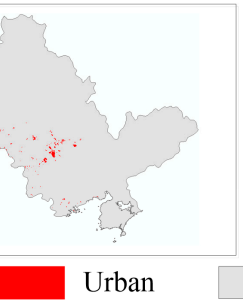

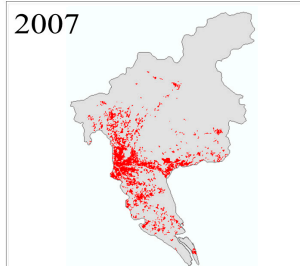

2007
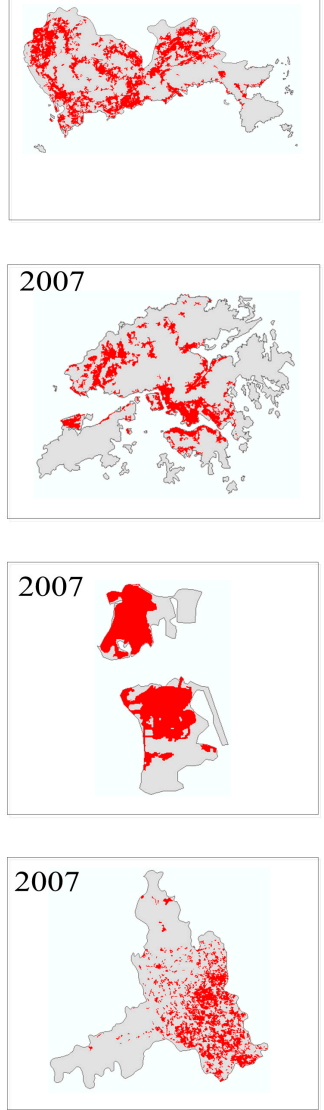

2007

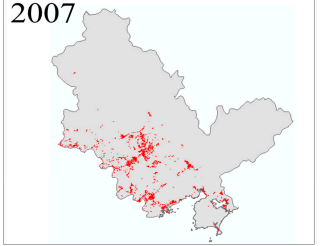

Non-urban
2017

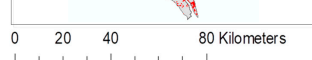

2017
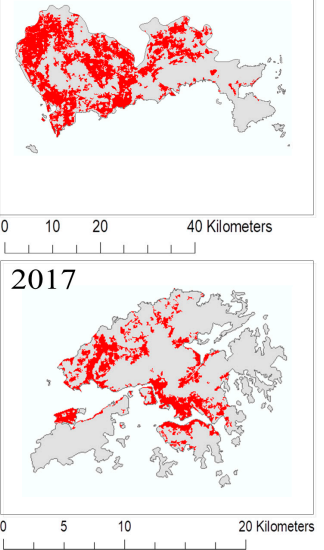

2017
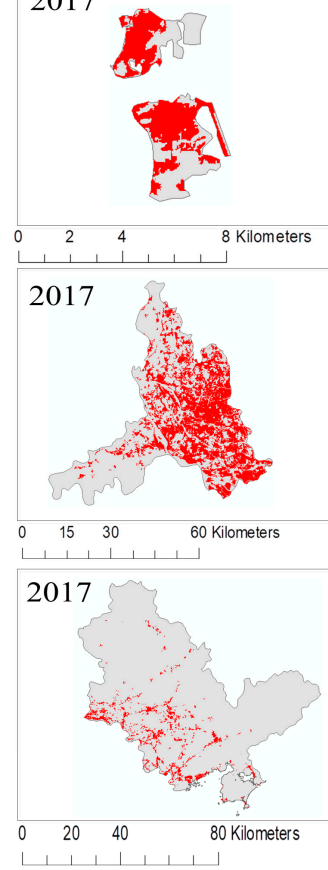

Figure 3. Cont. 
(g) Jiangmen
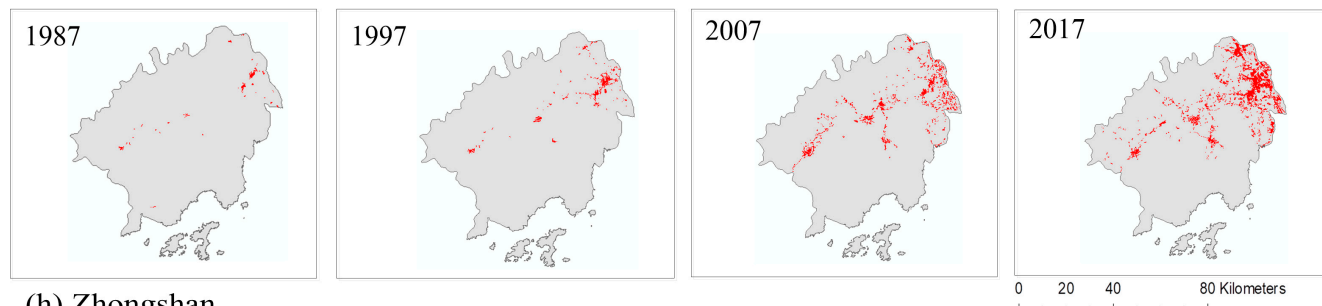

(h) Zhongshan
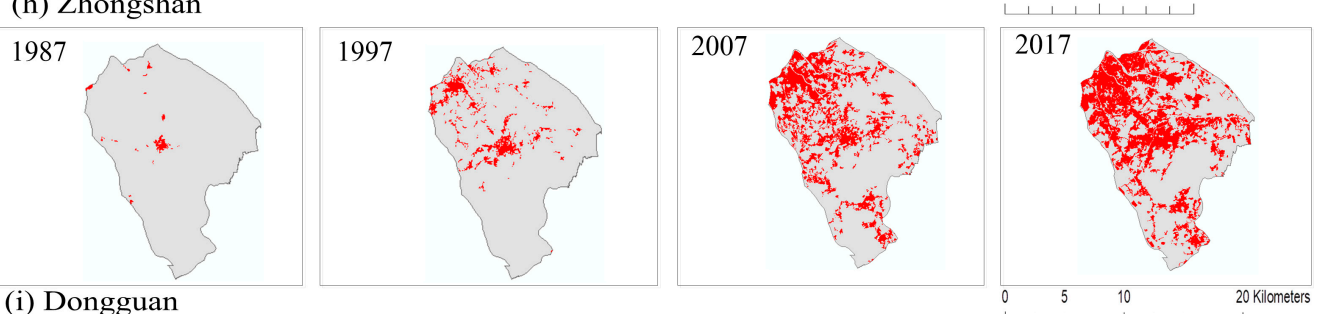

(i) Dongguan
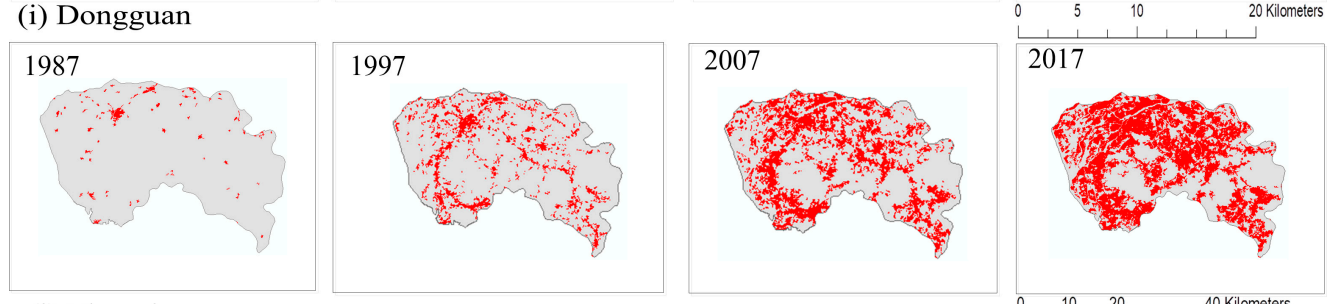

(j) Zhaoqing
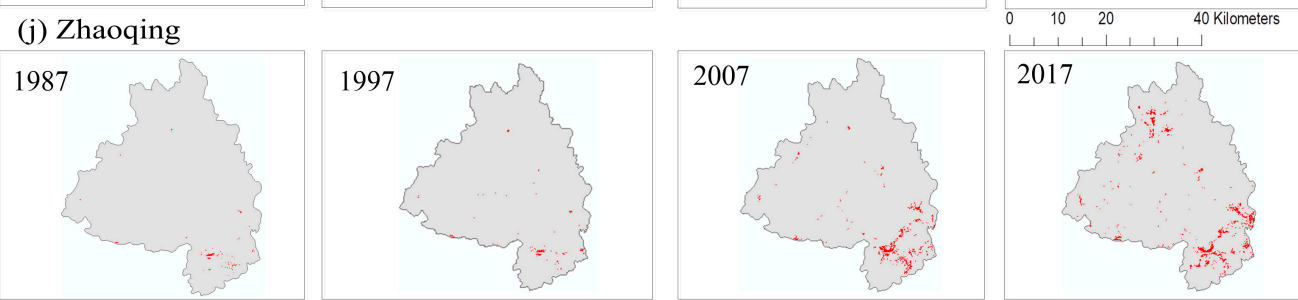

(k) Zhuhai
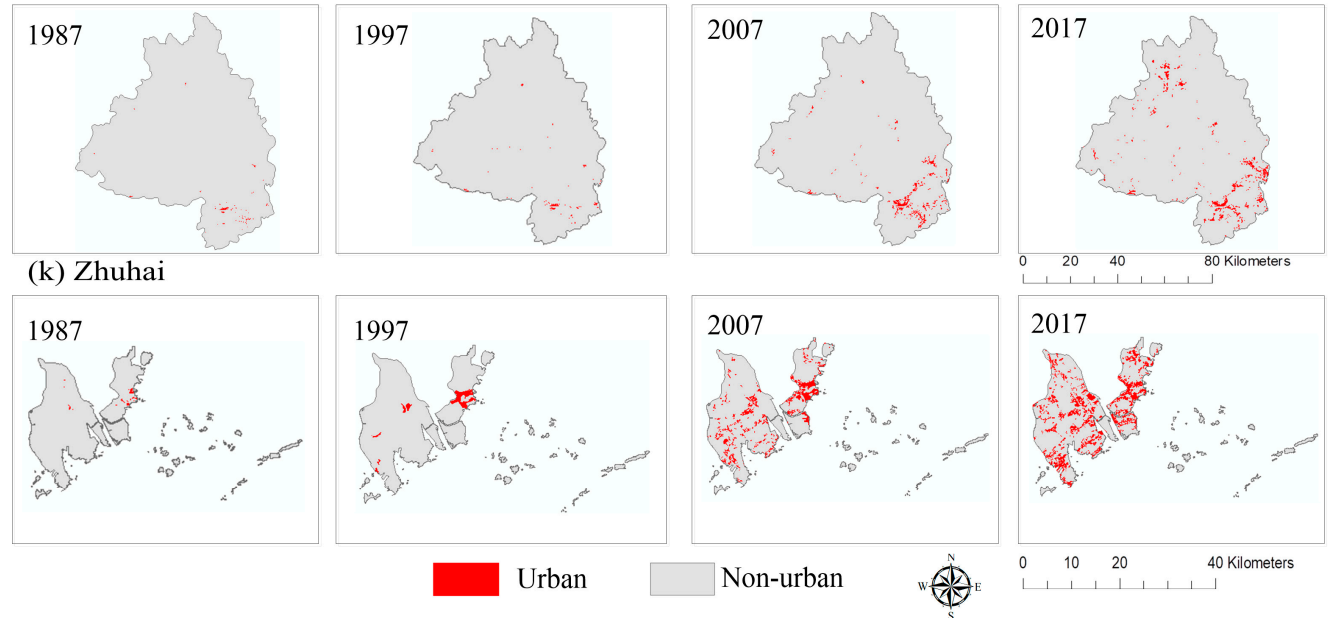

Figure 3. The urban areas of 11 cities within the Greater Bay Area (GBA) from 1987 to 2017.

Table 5. The evolution of the urban area in 11 cities in the GBA from 1987 to $2017\left(\mathrm{~km}^{2}\right)$.

\begin{tabular}{ccccccccc}
\hline Study Areas & \multicolumn{4}{c}{ Urban Areas } & \multicolumn{3}{c}{ Urban Area Changes } \\
\cline { 2 - 9 } & $\mathbf{1 9 8 7}$ & $\mathbf{1 9 9 7}$ & $\mathbf{2 0 0 7}$ & $\mathbf{2 0 1 7}$ & $\mathbf{1 9 8 7 - 1 9 9 7}$ & $\mathbf{1 9 9 7 - 2 0 0 7}$ & $\mathbf{2 0 0 7 - 2 0 1 7}$ & Average \\
\hline Guangzhou & 146.90 & 422.96 & 693.44 & 1486.24 & 276.06 & 270.48 & 792.8 & 446.45 \\
Shenzhen & 67.67 & 337.32 & 583.04 & 776.77 & 269.65 & 245.72 & 193.73 & 236.37 \\
Hong Kong & 91.29 & 124.92 & 183.56 & 203.42 & 33.63 & 58.64 & 19.86 & 37.38 \\
Macau & 4.87 & 7.32 & 17.23 & 18.45 & 2.45 & 9.91 & 1.22 & 4.53 \\
Foshan & 104.52 & 379.77 & 784.34 & 1485.32 & 275.25 & 404.57 & 700.98 & 460.27 \\
Huizhou & 46.12 & 60.27 & 337.54 & 535.37 & 14.15 & 277.27 & 197.83 & 163.08 \\
Jiangmen & 41.56 & 103.2 & 305.59 & 598.09 & 61.64 & 202.39 & 292.5 & 185.51 \\
Zhongshan & 17.03 & 123.67 & 426.09 & 631.22 & 106.64 & 302.42 & 205.13 & 204.73 \\
Dongguan & 46.15 & 336.93 & 764.48 & 1148.98 & 290.78 & 427.55 & 384.5 & 367.61 \\
Zhaoqing & 28.84 & 49.8 & 208.87 & 366.12 & 20.96 & 159.07 & 157.25 & 112.43 \\
Zhuhai & 10.50 & 49.78 & 176.77 & 316.58 & 39.28 & 126.99 & 139.81 & 102.03 \\
\hline
\end{tabular}


Table 6. Annual increase (AI), expansion rate (ER, \%), and annual growth rate (AGR, \%) for 11 cities in the GBA for three neighboring periods in 1987-2017.

\begin{tabular}{|c|c|c|c|c|c|}
\hline Index & City & 1987-1997 & 1997-2007 & 2007-2017 & Average \\
\hline \multirow[t]{11}{*}{ ER (\%) } & Guangzhou & 18.79 & 6.39 & 11.43 & 12.20 \\
\hline & Shenzhen & 39.85 & 7.28 & 3.32 & 16.82 \\
\hline & Hong Kong & 3.68 & 4.69 & 1.08 & 3.15 \\
\hline & Macau & 5.03 & 13.54 & 0.71 & 6.43 \\
\hline & Foshan & 26.33 & 10.65 & 8.94 & 15.31 \\
\hline & Huizhou & 3.07 & 46.00 & 5.86 & 18.31 \\
\hline & Jiangmen & 14.83 & 19.61 & 9.57 & 14.67 \\
\hline & Zhongshan & 62.62 & 24.45 & 4.81 & 30.63 \\
\hline & Dongguan & 63.01 & 12.69 & 5.03 & 26.91 \\
\hline & Zhaoqing & 7.27 & 31.94 & 7.53 & 15.58 \\
\hline & Zhuhai & 37.41 & 25.51 & 7.91 & 23.61 \\
\hline \multirow[t]{11}{*}{$\mathrm{AI}\left(\mathrm{km}^{2}\right)$} & Guangzhou & 27.61 & 27.05 & 79.28 & 44.65 \\
\hline & Shenzhen & 26.97 & 24.57 & 19.37 & 23.64 \\
\hline & Hong Kong & 3.36 & 5.86 & 1.99 & 3.74 \\
\hline & Macau & 0.25 & 0.99 & 0.12 & 0.45 \\
\hline & Foshan & 27.53 & 40.46 & 70.10 & 46.03 \\
\hline & Huizhou & 1.42 & 27.73 & 19.78 & 16.31 \\
\hline & Jiangmen & 6.16 & 20.24 & 29.25 & 18.55 \\
\hline & Zhongshan & 10.66 & 30.24 & 20.51 & 20.47 \\
\hline & Dongguan & 29.08 & 42.76 & 38.45 & 36.76 \\
\hline & Zhaoqing & 2.10 & 15.91 & 15.73 & 11.25 \\
\hline & Zhuhai & 3.93 & 12.70 & 13.98 & 10.20 \\
\hline \multirow[t]{11}{*}{ AGR (\%) } & Guangzhou & 11.15 & 5.07 & 7.92 & 8.05 \\
\hline & Shenzhen & 17.43 & 5.62 & 2.91 & 8.65 \\
\hline & Hong Kong & 3.19 & 3.92 & 1.03 & 2.71 \\
\hline & Macau & 4.16 & 8.94 & 0.69 & 4.59 \\
\hline & Foshan & 13.77 & 7.52 & 6.59 & 9.30 \\
\hline & Huizhou & 2.71 & 18.80 & 4.72 & 8.74 \\
\hline & Jiangmen & 9.52 & 11.47 & 6.95 & 9.31 \\
\hline & Zhongshan & 21.93 & 13.17 & 4.01 & 13.03 \\
\hline & Dongguan & 21.99 & 8.54 & 4.16 & 11.56 \\
\hline & Zhaoqing & 5.61 & 15.42 & 5.77 & 8.93 \\
\hline & Zhuhai & 16.84 & 13.51 & 6.00 & 12.12 \\
\hline
\end{tabular}

Figure 4 demonstrates the spatiotemporal distribution of the urban expansion in the 11 cities in 1987-2017. The urban areas of all cities increased year-by-year. The urban areas of Guangzhou and Foshan expanded around their original urban cores during 1987-1997, expanded in the east for Guangzhou and in the south for Foshan in 1997-2007, and finally formed a mononuclear polygon radiation pattern in 2017 (Figure 4a,e). The urban expansions in Macau and Zhongshan occurred around their original urban cores in 1987-1997, mainly in the northwest direction for Zhongshan and on the south coast for Macau in 1997-2007, and formed a double-nucleated polygon urbanization pattern in 2017 (Figure 4d,h). The urban expansions in Shenzhen, Hong Kong, and Dongguan were concentrated in their original cores with many growth polygons in 1987-1997, in the north direction for Shenzhen, the northwest and southeast directions for Hong Kong, and in nearly all directions for Dongguan in 1997-2007, and formed a multi-nuclear urbanization pattern in 2017 (Figure 4b,c,i). Regarding Huizhou, Jiangmen, Zhaoqing, and Zhuhai, their urban expansion situations were similar to those of Dongguan; however, the degree of urban expansion was relatively mild and presented a multi-nuclear urbanization pattern in 2017 (Figure 4f,g,j,k). It is worth noting that satellite towns and industrial parks appeared in 1997-2017 because of the urbanization of rural areas in suburbs of Guangzhou, Shenzhen, Foshan, Zhongshan, Dongguan, and Zhuhai (Figure 4a,b,e,h,i,k). 

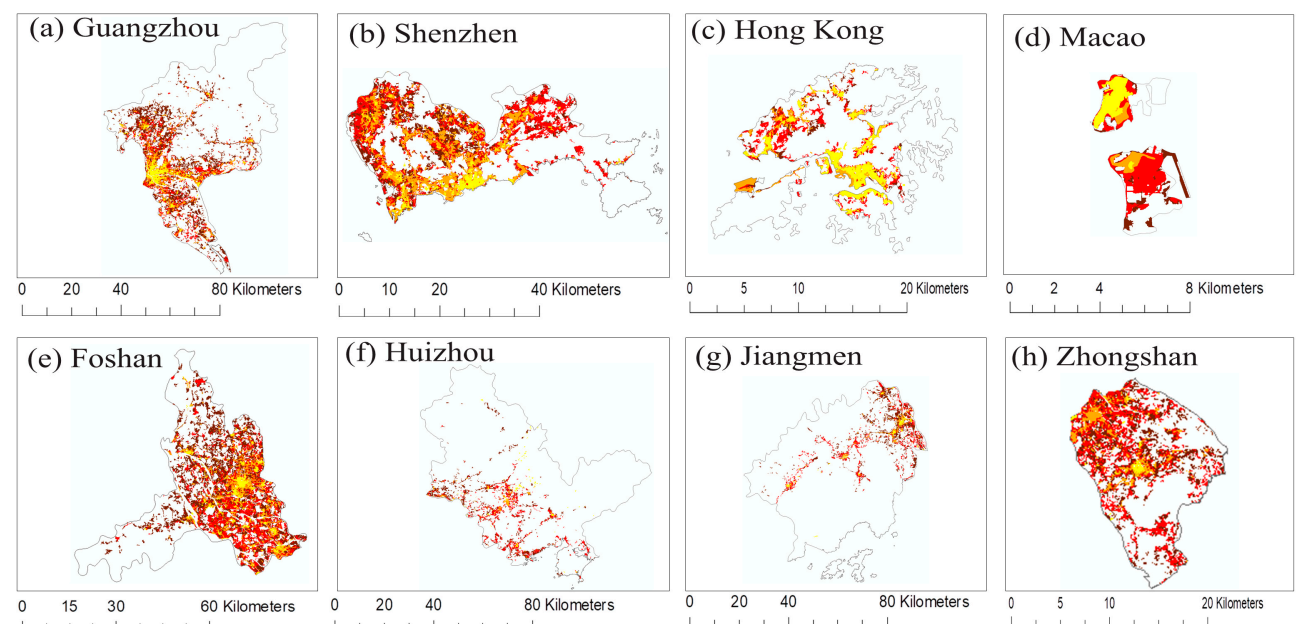

(f) Huizhou

(g) Jiangmen

(i) Dongguan
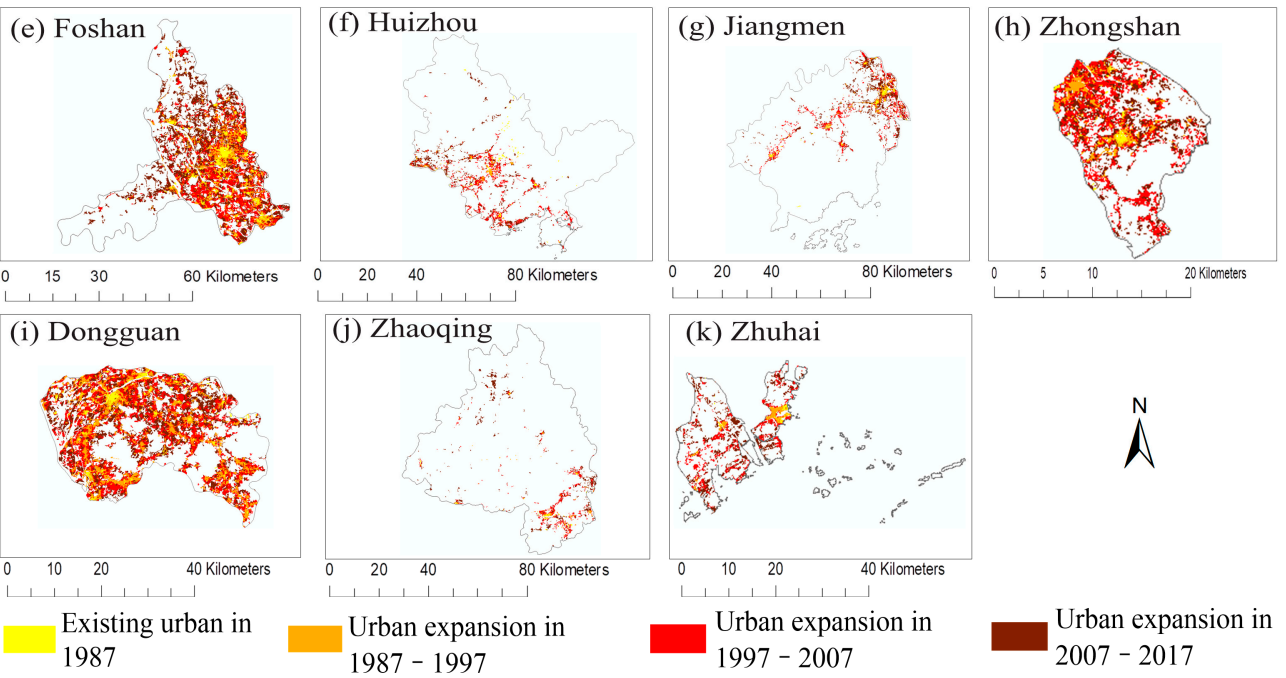

Figure 4. The spatial distribution of urban expansion in 11 cities in the GBA for three neighboring periods between 1987 and 2017.

\subsubsection{Urban Expansion Type}

Three urban expansion types (i.e., edge-expansion, outlying, and infilling) were used to reflect the spatial patterns of urban expansion in the 11 cities (Figure 5). Regarding Guangzhou and Foshan, outlying growth patches were distributed around their existing urban areas in 1987-1997, which were transferred to the south direction for Guangzhou and the north direction for Foshan in 1997-2007; since 2007, outlying growth patches have been distributed in all directions for Guangzhou and in the north and southwest directions for Foshan. Edge-expansion growth occurred in places that were on the peripheries of already-existing urban areas, and the gaps between these areas were filled by infilling growth over time, corroborating a mononuclear polygon radiation urbanization pattern in 2017 (Figure 5a,e). For Shenzhen, Hong Kong, Huizhou, Jiangmen, Dongguan, Zhaoqing, and Zhuhai, outlying growth patches were distributed sparsely at the outskirts, edge-expansion growth occurred in places that were close to already-existing urban areas, the inside and the edges of the existing urban areas were filled by infilling growth patches, and the three types of urban expansion expanded outwards in 1987-2017, corroborating a multinuclear urbanization structure (Figure 5b,c,f,g,i-k). It is worth noting that few outlying growth patches occurred in Shenzhen, Hong Kong, and Dongguan in 2007-2017 (Figure 5b,c,i). Regarding Macau and Zhongshan, outlying growth was mainly distributed in the northwest for Zhongshan in 1987-1997, and no outlying growth occurred for Macau in this period. After 1997, the outlying growth was distributed at the outskirts and the number of patches decreased. Edge-expansion patches occurred around the initial urban cores and an increasing to decreasing trend appeared in 1987-2017. Little infilling growth occurred in Macau and Zhongshan in 1987-1997, the inside and edges of the existing urban land areas were filled by infilling growth in 1997-2017, and infilling growth patches played an important role in linking the original urban cores and the edge-expansion growth in 2007-2017 (Figure 5d,h).

Figure 6 illustrates the percentage of the composition of the three urban expansion types between two neighboring periods in 1987-2017. In general, there are some similarities between the change in the number of patches and the proportion of area (Figure $6 \mathrm{a}, \mathrm{b}$ ) for all cities. The proportion of area 
of the infilling growth type increased in all cities, except for Zhuhai and Macau (Figure 6b), and the number of patches fluctuated (Figure 6a). Both the proportion of area and the number of patches of the outlying growth type decreased and the number of patches of the edge-expansion growth type increased in all cities, except for Macau, and the proportion of area of the edge-expansion growth type fluctuated. The 11 cities also showed differences in urban expansion type. With respect to the number of patches, the infilling growth type contributed the most to all 11 cities in the three periods, and the edge-expansion growth type followed closely. The number of patches of the outlying growth type accounted for the smallest proportion (less than 45\%), except for Huizhou (more than 50\% in 1987-1997) (Figure 6a). With regard to the proportion of area, compared with other cities, the infilling growth type was the one of the important types during 2007-2017 for Shenzhen, Hong Kong, Dongguan, Zhongshan, and Foshan. The edge-expansion and outlying growth types were the predominant types for all 11 cities, and the proportion of area of the outlying growth type in Huizhou, Jiangmen, Zhaoqing, and Zhuhai was much higher than that in other cities (Figure $6 b$ ).

(a) Guangzhou

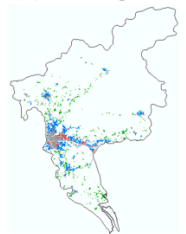

(c) Hong Kong

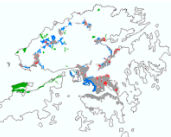

(e) Foshan

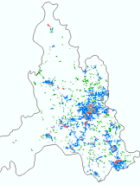

(g) Jiangmen

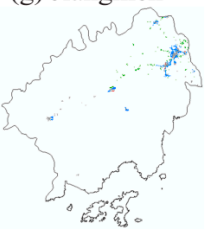

(i) Dongguan

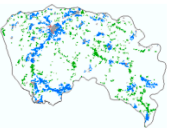

(k) Zhuhai

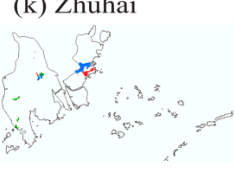

$.1987-1997$
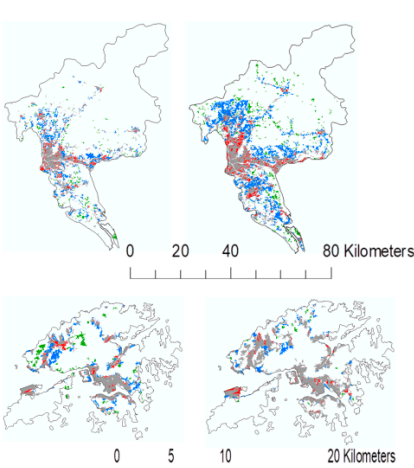

20 Kilometers

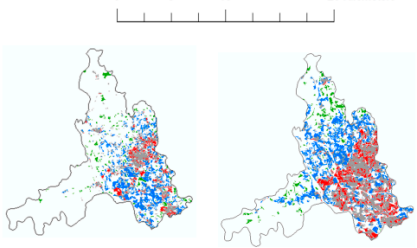

$0 \quad 15$

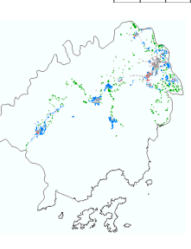

$0 \quad 20 \quad 40$

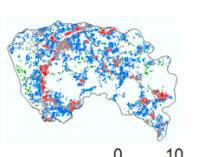

$0 \quad 10$

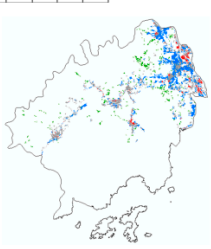

80 Kilometers

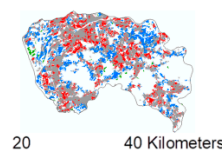

40 Kilometers

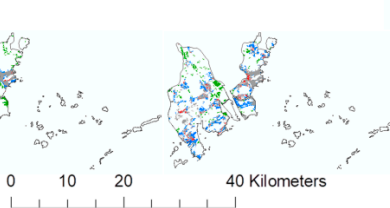

|I .1997-2007

III.2007-2017 (b) Shenzhen

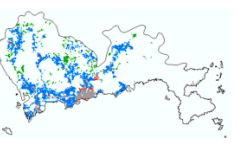

(d) Macao
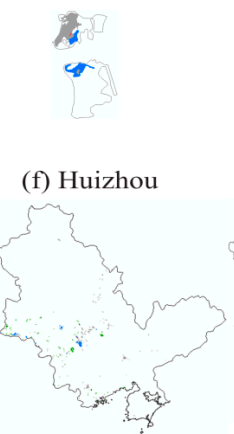

(h) Zhongshan

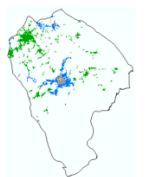

(j) Zhaoqing

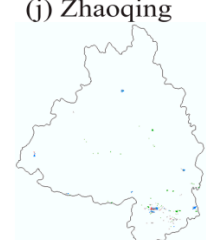

I .1987-1997

II .1997-2007

III.2007-2017

Existing urban

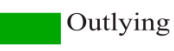

Edge-expansion
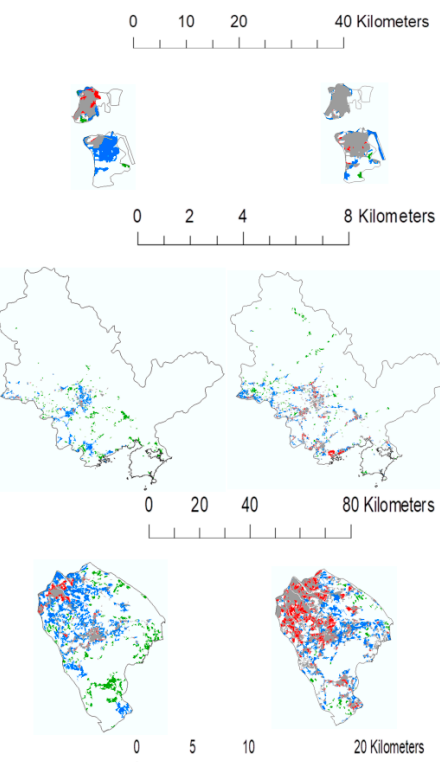

20 Kilometes

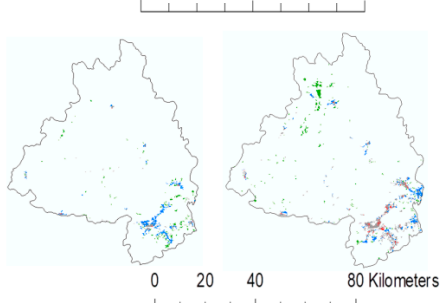

17

Figure 5. The spatial distribution of urban expansion types in all 11 cities in the GBA for three neighboring periods in 1987-2017. 


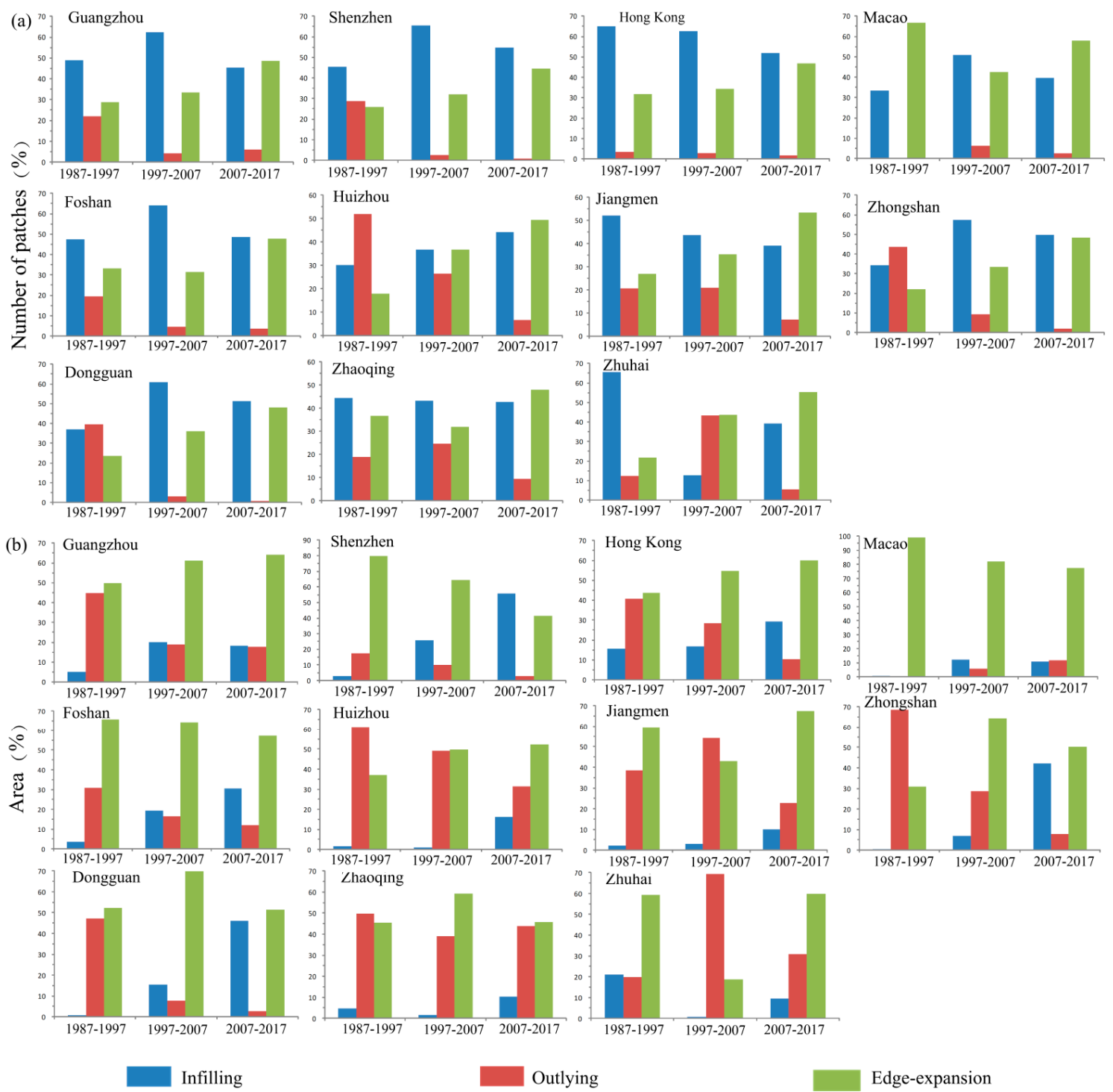

Figure 6. The composition (\%) of three urban expansion types for the area (a) and number of patches (b) of newly developed urban patches in 11 cities in the GBA in 1987-2017.

\subsection{Urban Landscape Pattern}

Figure 7 illustrates the trends and features of the landscape metrics for all cities under the impact of urbanization in 1987-2017. Generally, along with the promotion of urbanization, there was a monotonically increasing trend in PLAND and LPI for the 11 cities, with Macau, Shenzhen, and Dongguan having a much sharper trend compared with other cities (Figure 7a,d). The PLAND and LPI of Macau both exceeded the average of those of other cities, in addition to being overtaken by Dongguan in 2017, and Zhaoqing had the smallest value (Figure 7a,d). Regarding NP and FI, all cities presented a trend of a rapid increase and a rapid decline, respectively (Figure $7 \mathrm{~b}, \mathrm{f}$ ); however, the NP and FI fluctuated in different periods, with Guangzhou having the largest NP (Figure 7b). FI showed a downward trend in 1987-2017 for all cities (Figure 7f), which confirmed that the fragmentation and the complexity of the urban landscape were decreasing. Overall, the PD and LSI for all 11 cities showed an increasing trend from 1987 to 2017, except for Dongguan (where the PD and LSI declined after 1997), Zhongshan (where the PD and LSI declined after 2007), and Shenzhen (where PD and LSI had a declining trend after 1997 and 2007, respectively) (Figure 7c,e). Macau had a larger PD and a smaller LSI value, which confirmed its small urban area and high building density. 

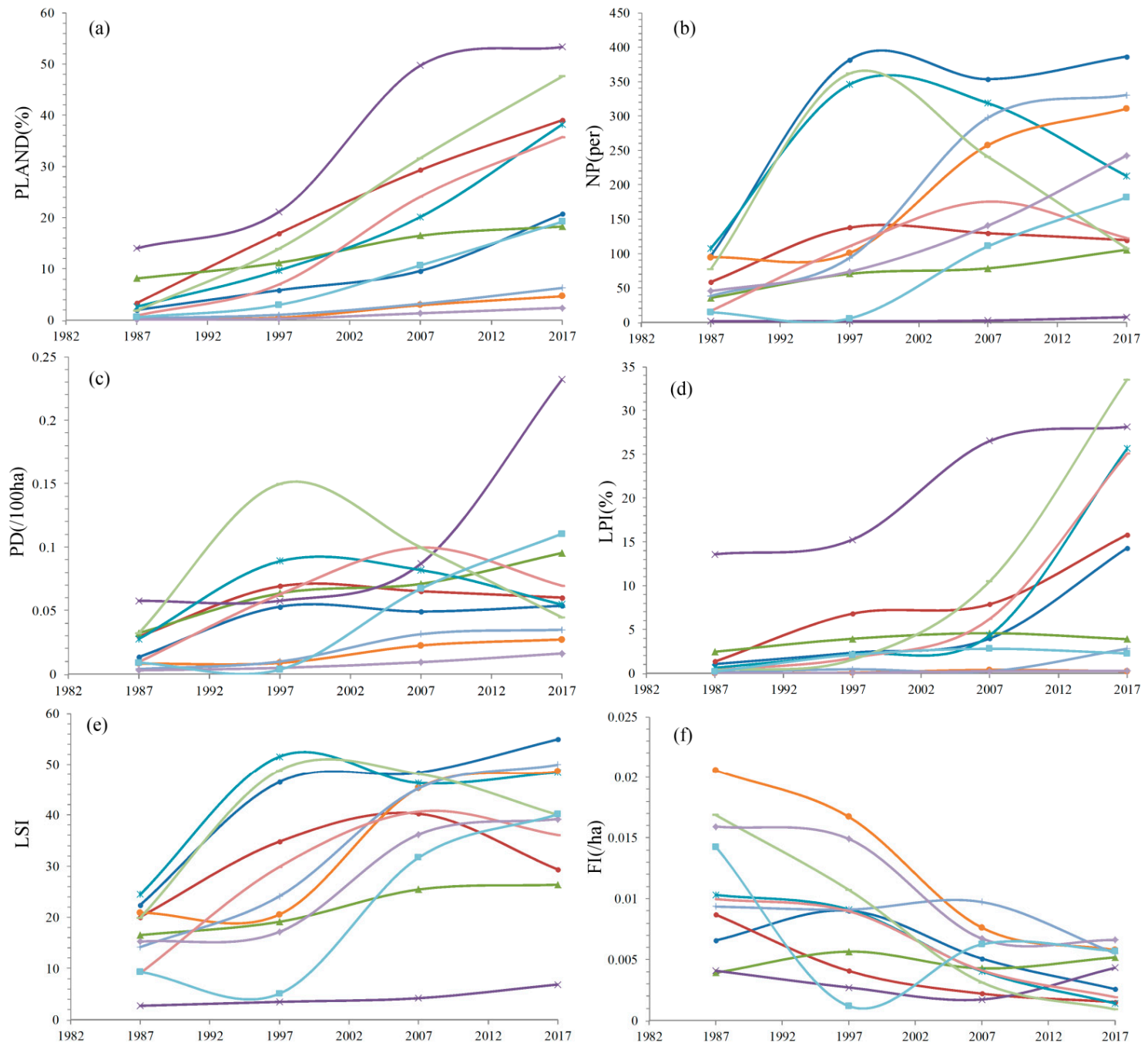

$$
\begin{aligned}
& \rightarrow \text { Guangzhou } \rightarrow \text { Shenzhen } \rightarrow \text { Hong Kong } \rightarrow \text { Macao } \rightarrow \text { Foshan } \rightarrow \text { Huizhou } \rightarrow \text { Jiangmen } \\
& - \text { Zhongshan } \rightarrow \text { Dongguan } \rightarrow \text { Zhaoqing } \rightarrow \text { Zhuhai }
\end{aligned}
$$

Figure 7. The landscape metrics for the urban land of 11 cities in the GBA between 1987 and 2017: (a) percentage of landscape (PLAND, \%); (b) number of patches (NP, per year); (c) patch density (PD, per $100 \mathrm{ha}$ ); (d) largest patch index (LPI, \%); (e) landscape shape index (LSI); and (f) fragmentation index (FI, per ha).

Figure 8 shows an analysis of patch composition at the microscopic scale, which provides the frequency distribution of the total area of urban land and the number of patches in accordance with the eight patch size classes in 1987-2017. Generally, along with an increase in the patch size classes for all cities over the entire period, there was a decrease in the increase in the number of patches (Figure 8a), and the total area of the patches maintained a positive correlation with the increase in patch size classes (Figure $8 b$ ). Differences were observed in the evolution of the number of patches and the total area for a fixed patch size class among all 11 cities. Small patches can be used to identify patterns of newly grown urban points; however, the contribution that small patches made to the total area was small. For example, the average ratio of small patches ranged from 0 to $0.5 \mathrm{~km}^{2}$ for all cities in 1987-2017, taking up more than $60 \%$ of the total number of patches (Figure 8a); however, the area ratio was less than 20\% for all cities except Huizhou and Zhaoqing, and less than 10\% for Hong Kong, Macau, Guangzhou, and Shenzhen (Figure 8b). Both the number and area percentage of the second and third smallest patch size classes, with a size of $0.5-1 \mathrm{~km}^{2}$ and $1-5 \mathrm{~km}^{2}$, respectively, occupied a relatively 
large proportion for all cities over time (Figure 8a,b). The largest patch of urban land reflects the dynamics of the urban core to some extent. For the different cities, only Guangzhou, Shenzhen, Foshan, Dongguan, Jiangmen, and Zhongshan had patches with an area of over $200 \mathrm{~km}^{2}$, which appeared after 2007 for Guangzhou and Dongguan and appeared in 2017 for the other cities (Figure 8b).
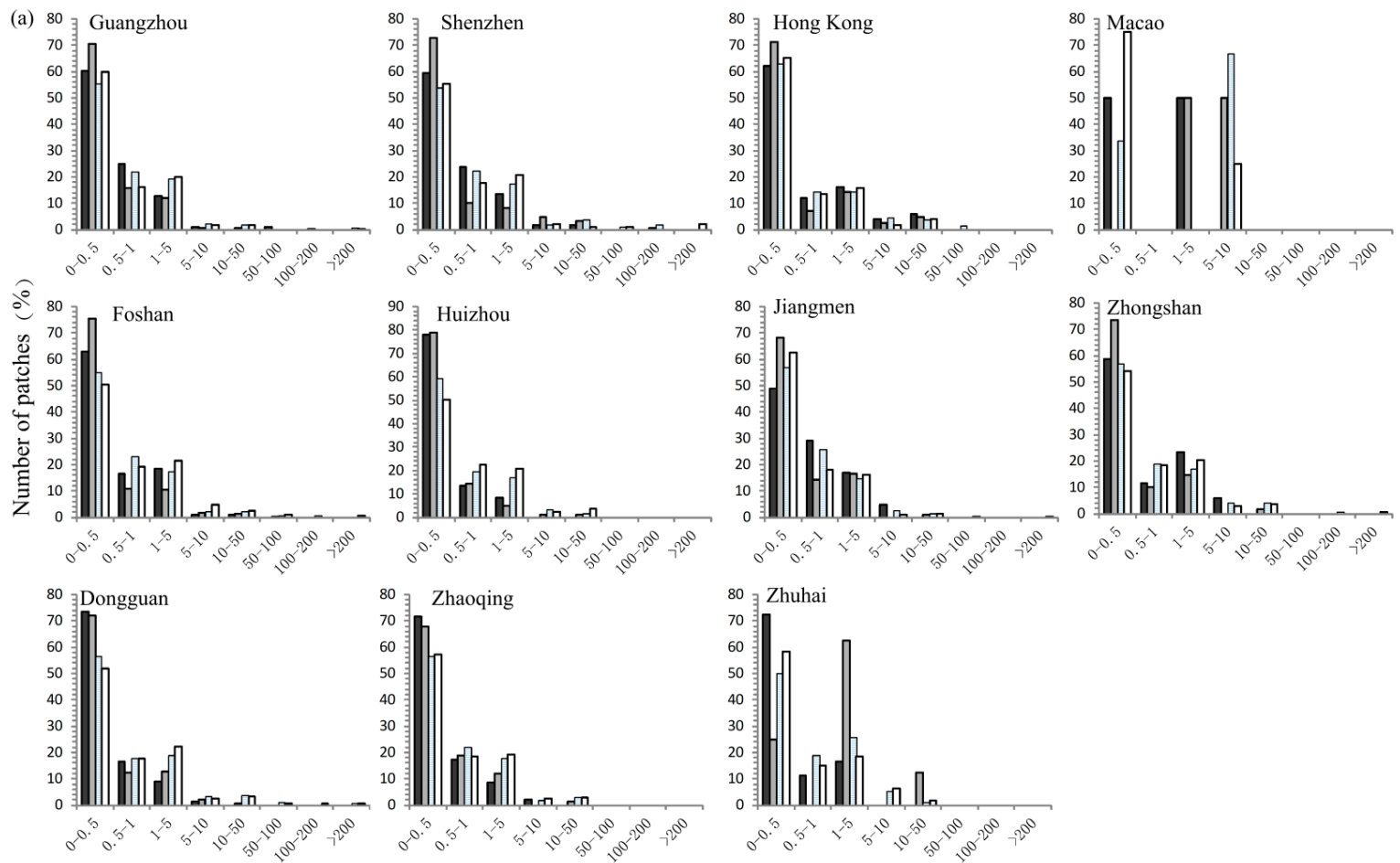

(b)
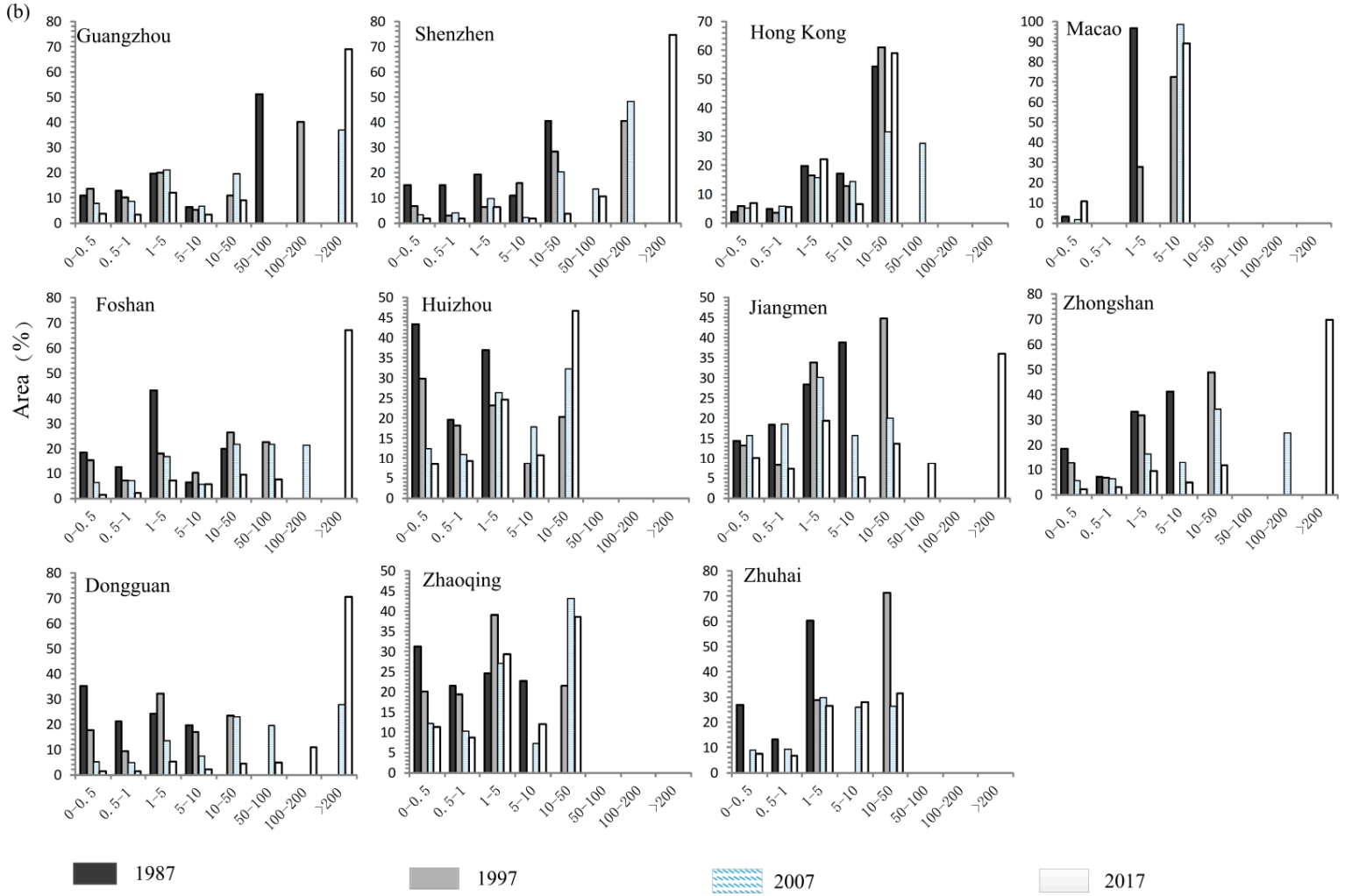

2017

Figure 8. The frequency distribution of the number of patches (a) and total area (b) of urban land in accordance with eight patch size classes (unit: $\mathrm{km}^{2}$ ) for 11 cities in the GBA between 1987 and 2017. 


\subsection{Rationality of Urban Expansion}

The rationality of urban expansion in all 11 cities was derived using Equations (6) and (7). The results are shown in Table 7 . The UPEC values varied across cities and time periods. The UPEC values of all cities were greater than 1.12, except for Shenzhen and Macau (1987-1997 and 2007-2017, respectively) (Table 7 and Figure 9a). The UPEC value for Guangzhou (1987-1997), Huizhou (1997-2007), Jiangmen (1987-2017), Zhongshan (1987-1997), and Zhaoqing (1987-2017) was greater than 10, which indicates that the efficiency of urban land use was extremely low in these periods (Figure 9a). In addition, the UGEC values also exhibited differences in all cities in 1987-2017. The UGEC values of all cities were less than 1, except for Huizhou (1997-2007), Jiangmen (1997-2007), and Zhaoqin (1997-2007), and values greater than 0.5 were obtained only for Guangzhou (2007-2017), Macau (1997-2007), Huizhou (1997-2007), Jiangmen (1997-2017), Zhongshan (1997-2007), Dongguan (1987-1997), Zhaoqing (1997-2007), and Zhuhai (1997-2007) (Figure 9b). Generally, the UGEC showed that the average annual rate of economic development exceeded the average annual rate of urban area expansion in all cities.

Table 7. The rationality of urban expansion in 11 cities in the GBA between 1987 and 2017. UPEC, urban area population elastic coefficient; UGEC, urban area gross domestic product (GDP) elastic coefficient.

\begin{tabular}{ccccccc}
\hline \multirow{2}{*}{ City } & \multicolumn{3}{c}{ UPEC } & \multicolumn{2}{c}{ UGEC } \\
\cline { 2 - 6 } & $\mathbf{1 9 8 7 - 1 9 9 7}$ & $\mathbf{1 9 9 7 - 2 0 0 7}$ & $\mathbf{2 0 0 7 - 2 0 1 7}$ & $\mathbf{1 9 8 7 - 1 9 9 7}$ & $\mathbf{1 9 9 7 - 2 0 0 7}$ & $\mathbf{2 0 0 7 - 2 0 1 7}$ \\
\hline Guangzhou & 12.10 & 1.51 & 2.17 & 0.22 & 0.20 & 0.66 \\
Shenzhen & 0.99 & 1.00 & 1.09 & 0.18 & 0.17 & 0.18 \\
Hong Kong & 2.23 & 8.60 & 1.55 & 0.16 & 0.44 & 0.16 \\
Macau & -17.91 & 5.21 & 0.31 & 0.23 & 0.89 & 0.04 \\
Foshan & 1.73 & 1.49 & 4.14 & 0.28 & 0.26 & 0.56 \\
Huizhou & 1.18 & 12.02 & 3.25 & 0.02 & 1.84 & 0.29 \\
Jiangmen & 16.34 & 18.33 & 11.57 & 0.25 & 1.24 & 0.66 \\
Zhongshan & 11.13 & 6.50 & 2.26 & 0.83 & 0.56 & 0.28 \\
Dongguan & 6.88 & 1.34 & 3.53 & 0.60 & 0.21 & 0.36 \\
Zhaoqing & 19.67 & 22.86 & 9.45 & 0.27 & 1.66 & 0.30 \\
Zhuhai & 4.03 & 5.63 & 4.01 & 0.27 & 0.90 & 0.42 \\
\hline
\end{tabular}

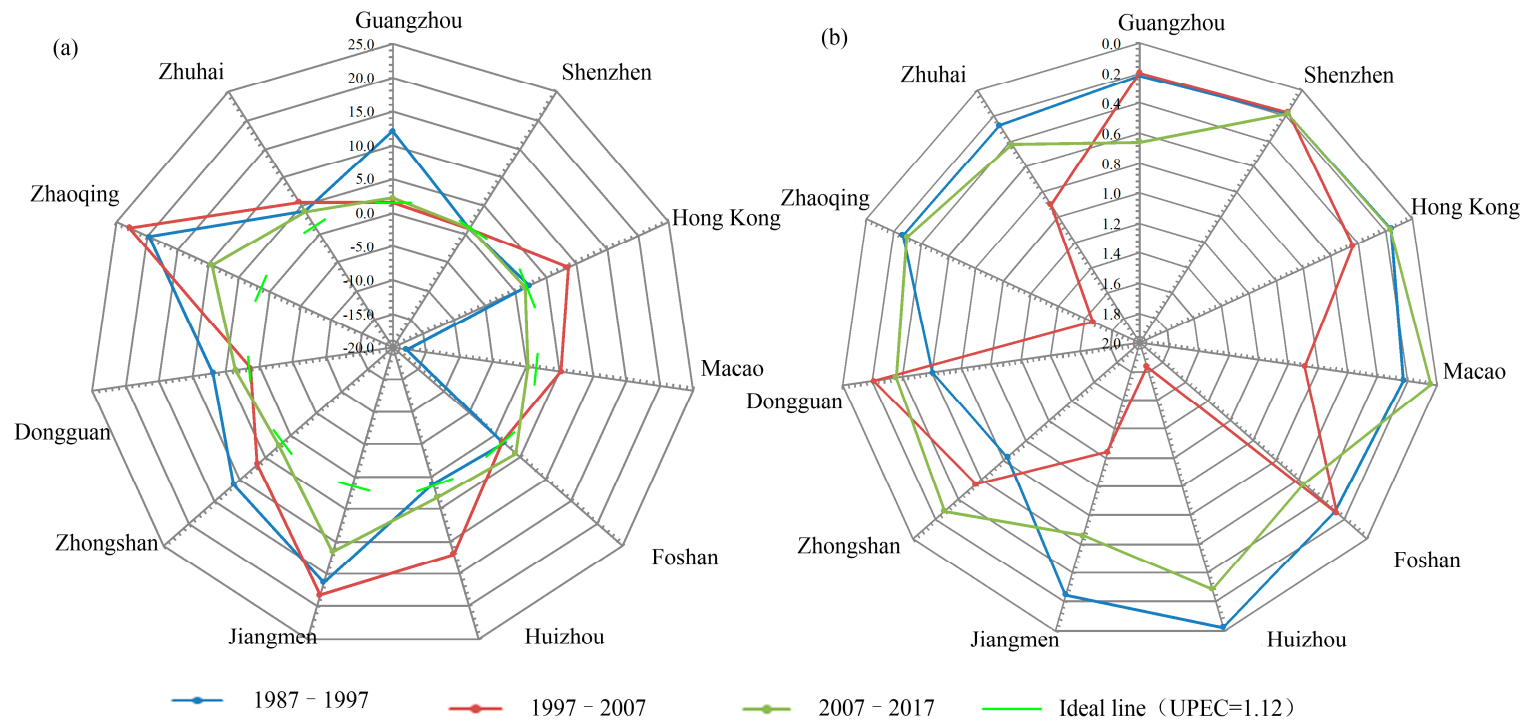

Figure 9. The rationality of urban expansion in 11 cities in the GBA between 1987 and 2017: (a) urban area population elastic coefficient (UPEC); and (b) urban area gross domestic product (GDP) elastic coefficient (UGEC). The farther the UPEC value deviates from the ideal line, the worse the rationality of urban expansion. 


\section{Discussion}

\subsection{Magnitude and Spatial Comparison of Urban Expansion}

The urban areas of the 11 cities in the GBA, particularly Guangzhou, Shenzhen, Foshan, Dongguan, and Zhuhai, expanded very quickly in 1987-2017 (Section 3.1). With respect to the change in urban area, Guangzhou, Shenzhen, Foshan, and Dongguan had the greatest magnitude of change in 1987-2017; the average magnitude exceeded $230 \mathrm{~km}^{2}$ as compared with other cities, and Hong Kong and Macau had the lowest magnitude of change (less than $40 \mathrm{~km}^{2}$ ). The differences in their history might be the reason for these results, in addition to natural controlling factors (i.e., special orographic), policy, population, and the GDP scale [88]. Historically speaking, Hong Kong and Macao were occupied by Britain and Portugal, respectively, after 1840; thus, they were developed earlier, and their urbanization rates slowed down after 1990. With regard to natural controlling factors, Macao is surrounded by the ocean and its total land area is less than $40 \mathrm{~km}^{2}$, which might impose a limit upon the expansion of its urban area. Hong Kong is mountainous; its flat terrain only accounts for $16 \%$ of the total area, and the other $84 \%$ of the area is not suitable for urban construction and agricultural development [91]; moreover, urban growth of Hong Kong is especially in the third dimension, thus, urban expansion in Hong Kong is limited, corresponding to the smallest average growth rates. With regard to policy, onerous land laws have restricted the urban expansion of Hong Kong to a large extent, and about $75 \%$ of the total land remains undeveloped [92]. Moreover, Macau and Hong Kong advocate for a free-trade economic system and attract a large amount of capital for the construction of infrastructure, which can significantly facilitate the development of urban areas in their early stages. Nevertheless, the policies of reform and opening-up greatly promoted the development of coastal cities on the mainland after 1978 [93,94], particularly during 1987-1997. The population and GDP of Guangzhou and Shenzhen have increased exponentially, with a population of greater than 10 million and a GDP of 300 billion U.S. Dollars in 2017, respectively. These two cities occupy almost one-third of the GBA. As has been demonstrated in many studies, population and GDP are the major forces that drive urban expansion [95-97]; therefore, the large population and GDP of Guangzhou, Shenzhen, Foshan, and Dongguan may have produced the large magnitude of the change in urban area. It is worth noting that Guangzhou, Shenzhen, Foshan, and Dongguan are geographically connected; hence, urban expansion in these cities might be attributed to the driving factors that they have in common.

In terms of growth type, a transition from the outlying growth type to the infilling and edge-expansion growth types occurred during the urban expansion in the 11 cities, and several different urban expansion patterns were observed (Section 3.1). The terrain, transportation, and policies regarding urban planning might have led to some spatial similarities and unique features in the urban expansion within each city. The Pearl River system, expressways, and railways provide convenient traffic conditions and a large number of ports. These advantages promote the development of Guangzhou, Shenzhen, Foshan, Dongguan, and Zhongshan; hence, large urban patches are disseminated along the Pearl River and harbor zone, and they are connected through Guangzhou-Foshan, Guangzhou-Shenzhen, Guangzhou-Shenzhen-Dongguan, and Shenzhen-Zhongshan roads. During the early period of development, all these cities expanded in patterns that maintained a close relationship with their policies and physical factors. As has been indicated in previous studies, there is a close relationship between urban expansion patterns and urban planning and policy [79,98], and all 11 cities were no exception in this regard. For example, Huizhou, Zhaoqing, and Jiangmen had a much larger amount of outlying growth in 1987-2017 than the other cities, which were in a close relationship with their land area sizes, local policies, and transportation infrastructure. Their large areas, unfavorable traffic conditions caused by the distribution of mountains, and differences in local policies resulted in their urban expansion not being concentrated, corresponding to their large amount of outlying growth. In addition, local governments established satellite towns and industrial parks based on urban planning policies whose purpose was to control excessive urban expansion and evacuate overloaded industries and populations in the urban core $[99,100]$. Therefore, many industrial parks and satellite towns 
emerged in the rural areas of Guangzhou, Shenzhen, Foshan, Zhongshan, Dongguan, and Zhuhai in 1997-2017. Moreover, Shenzhen and Dongguan experienced a larger amount of infilling growth in 2007-2017 than the other cities because, in 1987-2007, these two cities occupied a large area of open land, and there was less open space for outward expansion; therefore, there was a high proportion of infilling growth in 2007-2017.

\subsection{Response of Landscape to Urban Expansion}

The effect of urban expansion on a landscape varies across temporal and spatial scales [101,102], and there is an increase in a landscape's degree of irregularity and fragmentation during the early stages of urbanization according to Collinge [103]. Our previous study also showed that, in the GBA at the regional level, the landscape's degree of irregularity and fragmentation took on a tendency to first rise and then drop as a result of urbanization [56]. In the present study, we analyzed the influence of urban expansion on the landscape at a city level. At the city level, the urbanization of most cities took on an urban-to-rural gradient, and the farther away the phenomenon was from the urban core, the more obvious it was. Shenzhen, Hong Kong, Dongguan, Jiangmen, Huizhou, Zhaoqing, and Zhuhai showed an obvious urban-to-rural gradient in their respective urban areas, and their large urban patches (a patch area $>10 \mathrm{~km}^{2}$ ) expanded from the original urban cores to suburban basins. On the other hand, the few growth points that were relatively small were swallowed by the large urban patches in 1987-2017, corresponding to their multi-nuclear urbanization pattern. Guangzhou and Foshan exhibited a gradient in their respective urban areas, with their large urban patches appearing after 1987, which resulted from the edge-expansion of the original urban cores in response to their mononuclear polygon radiation pattern of urbanization. A gradient in the urban area with large urban patches appeared after 1987 in Zhongshan and after 1997 in Macau, corresponding to a double-nucleated polygon urbanization pattern. Generally, all cities took on a clear gradient in the urban area, and the small and large urban patches developed from the original urban cores as time passed. Moreover, in order to reach a balance between urban intensification and extensification, urban planners established many industrial parks and satellite towns in the suburbs of different cities within the GBA in 1997-2017, corresponding to the urban-to-rural gradient of the urban landscape in Guangzhou, Shenzhen, Foshan, Zhongshan, Dongguan, and Zhuhai.

Furthermore, as has been demonstrated in several studies, the relationship between urban form and landscape is of paramount importance to an urban ecosystem's stability and integrity $[79,104,105]$, and the urban planning rule of adjoining existing roads or waterways promotes the connectivity in a landscape compared with the rule of adjoining buildings or parcels of open land [106], which may be the reason why the connectivity of Huizhou, Zhaoqing, and Zhuhai was lower than that of the other cities. It is worth noting that since urban ecological connectivity is complex, it should be compared across cities in a future study.

\subsection{Rationality of Urban Expansion}

The results of this study showed that all cities experienced rapid urbanization, and the rationality of most cities' expansions exceeded the rational level. Theoretically, the speed of urban expansion should be appropriate for the growth rate of the urban population. When urban expansion exceeds urban population growth, it will inevitably cause land resources to be wasted. In contrast, when urban population growth far exceeds urban expansion, the urban land use intensity will be too high, as was the case for Hong Kong and Macau (Figure 10a), which will also lead to the deterioration of the urban environment and a decline in residents' living conditions [57]. Some studies have shown that the urban area growth rate should be slightly higher than the urban population growth rate in China, where the urban population density is relatively high and there is insufficient infrastructure [107,108]. Therefore, we conclude that, in the GBA, some cities' expansions were reasonable in certain periods, such as Guangzhou (1997-2007), Hong Kong (2007-2017), Foshan (1987-2007), Huizhou (1987-1997), and Dongguan (1997-2007). The fact that the UPEC value for most cities in this study was found to 
exceed the rationality level was mainly attributable to the rapid economic development under China's reform and opening-up policy, particularly in the coastal cities (Figure 10b). Residents' improved purchasing power, living standards, and notions of consumption, plus the increased demand for housing, transportation, a more comfortable way of life, and other infrastructure, have promoted the development of the real estate industry and boosted investment in the construction of infrastructure, corresponding to an increase in the urban land area and higher UPEC values. It is worth noting that the UPEC value of Shenzhen was less than 1.12 in 1987-2017. This result may have been the result of Shenzhen attracting a large number of migrants and a floating population from all over the country [109]; therefore, the urban area growth rate was not able to keep up with the population growth rate. In addition, the UPEC value of Macau was -17.91 in 1987-1997, which may have been caused by the population decline (from 434.3 thousand in 1987 to 422.1 thousand in 1997). Moreover, along with the process of reform and opening-up, China's economy was rapidly developing, and the GDP grew exponentially in the GBA [110]. However, the observed urban area expanded in multiple cities, which confirmed the low UGEC value.
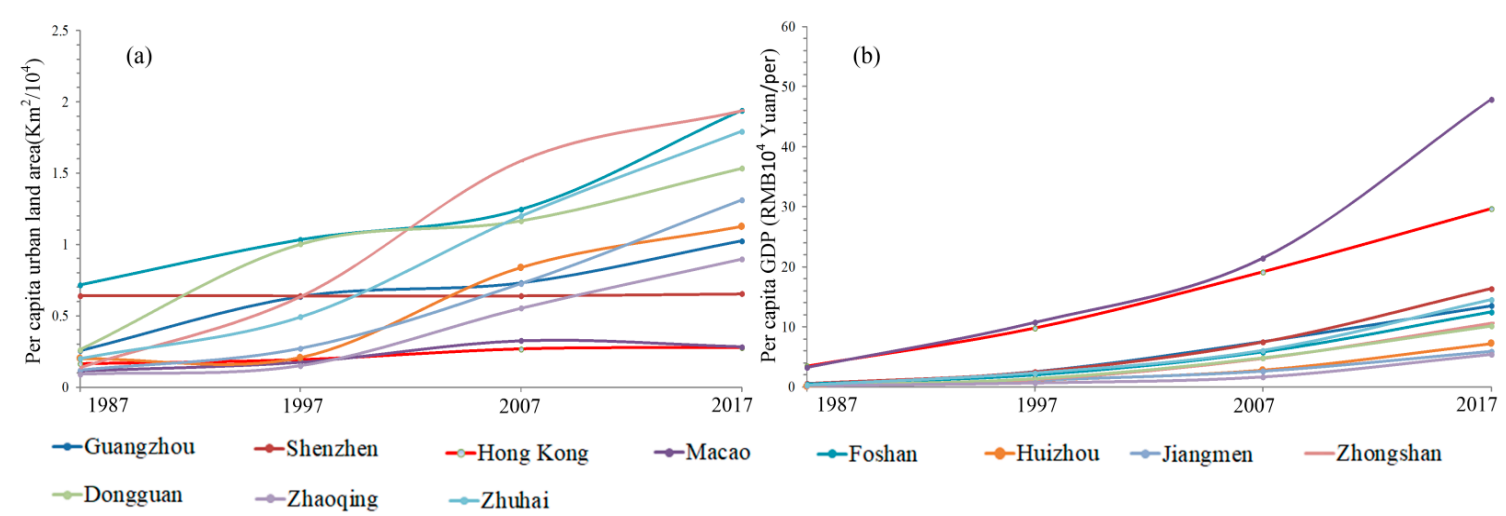

Figure 10. The per capita urban land area (a) and per capita GDP (b) of different cities in the GBA from 1987 to 2017.

Excessive urbanization not only results in environmental problems, including an elevated land surface temperature, a low amount of vegetation in urban areas, and arable land losses, but generates social problems, such as traffic jams, inadequate infrastructure and housing, and a high unemployment rate $[43,111]$. Hence, it is necessary for all cities to determine the influence of urban expansion on the natural environment. Fortunately, for the purpose of restricting urban expansion and protecting the environment in China, the Chinese government defined an ecological red line [112], and it is required to complete the demarcation before the end of 2020 [113]. Therefore, it is foreseeable that the velocity and intensity of urban expansion in all 11 studied cities will not increase significantly in the future. Local governments and urban planners can plan an ecological red line based on our observed results to protect the natural environment. For example, although the establishment of satellite towns and industrial parks in the suburbs solved the urban intensification problem, some of the satellite towns and industrial parks in Foshan, Zhongshan, and Dongguan occupy a large amount of forestland/cultivated land and have caused land resources to deteriorate and be wasted. Therefore, ecological red lines for the undeveloped suburbs of these cities are necessary. Moreover, some abandoned or sparsely populated industrial parks in Foshan, Zhongshan, and Dongguan need to be demolished in order to restore the eco-environment. It is worth noting that urban planners can reduce the degree of occupation of suburban land in these cities through urban renewal (i.e., urban development in the third dimension). 


\subsection{Limitation and Future Work}

Although the spatiotemporal characteristics and rationality of the urban expansion within the GBA were identified in this study, some limitations and future works need to be mentioned. Firstly, the resolution of the used Landsat images was $30 \mathrm{~m}$, which made it difficult to obtain more precise urban area boundaries; thus, further research that uses different remote sensing data (e.g., high-resolution remote sensing images) for urban land classification may strengthen our results. Secondly, the forces that drive urban expansion vary across cities, and the difference of land use types within cities also affects urban growth types; thus, research on the socioeconomic forces and the transfer of different land use types that drive urban expansion in these cities should be conducted. In addition, UPEC and UGEC are used as proxies to measure the rationality of urban expansion in this study. However, they might not fully depict the rationality of urban expansion, because other factors might also determine whether an urban area develops in a sustainable way. For example, urban expansion in the third dimension is a common phenomenon in the urbanization process, and the rationality of urban expansion in the third dimension cannot be evaluated with the UPEC and UGEC. Therefore, we need to improve the method that we used to evaluate the rationality of urban expansion by combining digital surface model (DSM), synthetic aperture radar (SAR), and interferometric synthetic aperture radar (InSAR) data in the future. Finally, in order to help local governments balance urban development and eco-environment protection, there is an urgent need to study the ecological effects of urban expansion.

\section{Conclusions}

The spatiotemporal features and rationalities of urban expansions within the Guangdong-Hong Kong-Macau Greater Bay Area of China in 1987-2017 were analyzed in this study by combining remote sensing, landscape analysis, and GIS techniques. All 11 studied cities experienced unprecedented urban growth, particularly Guangzhou, Shenzhen, Foshan, Dongguan, Zhongshan, and Zhuhai. The urban areas of Guangzhou, Shenzhen, Foshan, Dongguan, Zhongshan, and Zhuhai expanded from 146.90, $67.67,104.52,46.15,17.03$, and $10.50 \mathrm{~km}^{2}$, respectively, in 1987 to $1486.24,776.77,1485.32,1148.98,631.22$, and $316.58 \mathrm{~km}^{2}$, respectively, in 2017. The spatial patterns of urban expansion in all cities experienced a shift from the outlying expansion type to the edge-expansion and infilling expansion types over time, and the composition of the urban expansion types varied across cities and study periods. The rationality of all cities' expansions exceeded the rational level, except for Guangzhou (1997-2007), Hong Kong (2007-2017), Foshan (1987-2007), Huizhou (1987-1997), and Dongguan (1997-2007). All 11 cities possess opportunities for, and face challenges in, the development and balancing of regional economic and ecological benefits, and it is hoped that the information obtained in this study will help policyand decision-makers to sustainably develop the Guangdong-Hong Kong-Macau Greater Bay Area.

Author Contributions: C.Y. conducted the data analyses and prepared the manuscript; C.Y., Q.L., T.Z., T.S., H.L., W.G., and G.W. developed the methodology; C.Y. contributed to the experiments; and Q.L., T.Z., G.W., and M.G. provided valuable insights and edited the manuscript. All the authors contributed to the discussion part and provided guidance and editing for the complete work.

Funding: This research received the funding of the National Natural Science Foundation of China (No. 41890854), the Basic Research Program of Shenzhen Science and Technology Innovation Committee (No. JCYJ20180507182022554), the National Natural Science Foundation of China (No. 7181101150), the Shenzhen Future Industry Development Funding Program (No. 201507211219247860), and the Basic Research Program of Shenzhen Science and Technology Innovation Committee (No. JCYJ20170302144323219).

Acknowledgments: We would like to express our great thanks to the National Natural Science Foundation of China (No. 41890854, 7181101150), the Basic Research Program of Shenzhen Science and Technology Innovation Committee (No. JCYJ20180507182022554, JCYJ20170302144323219), the Shenzhen Future Industry Development Funding Program (No. 201507211219247860).

Conflicts of Interest: The authors declare no conflicts of interest. 


\section{References}

1. World Bank. World Bank Database. Available online: http://data.worldbank.org (accessed on 13 May 2015).

2. Madanian, M.; Soffianian, A.R.; Koupai, S.S.; Pourmanafi, S.; Momeni, M. Analyzing the effects of urban expansion on land surface temperature patterns by landscape metrics: A case study of Isfahan city, Iran. Environ. Monit. Assess. 2018, 190, 189-199. [CrossRef] [PubMed]

3. United Nations. World Urbanization Prospects: The 2014 Revision; UN: New York, NY, USA, 2014.

4. Turner, B.L.; Lambin, E.F.; Reenberg, A. The emergence of land change science for global environmental change and sustainability. PNAS 2007, 104, 20666-20671. [CrossRef] [PubMed]

5. Zhao, S.; Da, L.; Tang, Z.; Fang, H.; Fang, J. Ecological consequences of rapid urban expansion: Shanghai, China. Front. Ecol. Environ. 2006, 4, 341-346. [CrossRef]

6. Shen, W.; Wu, J.; Grimm, N.B.; Hope, D. Effects of urbanization-induced environmental changes on ecosystem functioning in the phoenix metropolitan region, USA. Ecosystems 2008, 11, 138-155. [CrossRef]

7. Clarke, K.C.; Gaydos, L.J. Loose-coupling a cellular automaton model and GIS: Long-term urban growth prediction for San Francisco and Washington/Baltimore. Int. J. Geogr. Inf. Sci. 1998, 12, 699-714. [CrossRef] [PubMed]

8. Allen, J.; Lu, K. Modeling and prediction of future urban growth in the Charleston region of South Carolina: A GIS-based integrated approach. Ecol. Soc. 2003, 8, 1850-1851. [CrossRef]

9. Yangfan, L.I.; Zhu, X.; Sun, X.; Wang, F. Landscape effects of environmental impact on bay-area wetlands under rapid urban expansion and development policy: A case study of Lianyungang, China. Landscape Urban. Plan. 2010, 94, 218-227.

10. Sun, R.H.; Xu, Z.L.; Chen, L.X.; Li, F. Theoretical framework and key techniques of urban ecological landscape research. Acta Ecol. Sin. 2012, 32, 979-1986.

11. Shao, M.; Tang, X.; Zhang, Y.; Li, W. City clusters in China: Air and surface water pollution. Front. Ecol. Environ. 2006, 4, 353-361. [CrossRef]

12. Zhu, H.M.; You, W.H.; Zeng, Z.F. Urbanization and $\mathrm{CO}_{2}$ emissions: A semi-parametric panel data analysis. Econ. Lett 2012, 117, 848-850. [CrossRef]

13. Radulovic, S.; Bobic, A.; Cvejic, J.; Tutundzic, A. Growing cities in serbia in the light of projected global warming: The situation in urban morphological zones. Urban. Fore. Urban. Gree. 2015, 14, 99-106. [CrossRef]

14. Keshtkar, H.; Voigt, W. Potential impacts of climate and landscape fragmentation changes on plant distributions: Coupling multitemporal satellite imagery with GIS-based cellular automata model. Ecol. Inform. 2016, 32, 145-155. [CrossRef]

15. NBSC. China's City Construction Statistical Yearbook of 2011; China Statistics Press: Beijing, China, 2012.

16. World Bank. Urban Population. Available online: http://www.data.worldbank.org (accessed on 24 February 2012).

17. Liu, J.; Zhuang, D.; Luo, D.; Xiao, X. Land-cover classification of China: Integrated analysis of AVHRR imagery and geophysical data. Int. J. Remote Sens. 2003, 24, 2485-2500. [CrossRef]

18. Zhou, X.; Chen, L.; Xiang, W.N. Quantitative analysis of the built-up area expansion in Su-Xi-Chang region, China. Chin. J. Appl. Ecol 2014, 25, 1422-1430.

19. Zen, Y.N.; He, L.L.; Jin, W.; Wu, K.J.; Xu, Y.Y.; Yu, F.F. Quantitative Analysis of the Urban Expansion Models in Changsha-Zhuzhou-Xiangtan Metroplan Areas. Sci. Geogr. Sin. 2012, 32, 544-549.

20. Fang, C. Urbanization and urban development in China after the reform and opening-up. Econ. Geogr. 2009, $29,19-25$.

21. Zhou, L.M.; Dickinson, R.E.; Tian, Y.H. Evidence for a significant urbanization effect on climate in China. PNAS 2004, 101, 9540-9544. [CrossRef] [PubMed]

22. Chan, C.K.; Yao, X. Air pollution in mega cities in China. Atmos. Environ. 2008, 42, 1-42. [CrossRef]

23. Zhu, D.J.; Yu, W.H.; Sun, X.H. Urban expansion and farmland protection policy. Chin. Land Sci. 1996, 10, 36-37.

24. Ma, T.; Zhou, C.H.; Pei, T.; Haynie, S.; Fan, J. Quantitative estimation of urbanization dynamics using time series of DMSP/OLS nighttime light data: A comparative case study from China's cities. Remote Sens. Environ. 2012, 124, 99-107. [CrossRef]

25. Yu, W.; Zhou, W. The spatiotemporal pattern of urban expansion in china: a comparison study of three urban megaregions. Remote Sens. 2017, 9, 45. [CrossRef] 
26. Xiao, J.; Shen, Y.; Ge, J.; Tateishi, R.; Tang, C.; Liang, Y. Evaluating urban expansion and land use change in Shijiazhuang, China, by using GIS and remote sensing. Landsc. Urban. Plan. 2006, 75, 69-80. [CrossRef]

27. Wang, L.; Li, C.C.; Ying, Q.; Cheng, X.; Wang, X.Y.; Li, X.Y.; Hu, L.Y.; Liang, L.; Yu, L.; Huang, H.B.; et al. China's urban expansion from 1990 to 2010 determined with satellite remote sensing. Sci. Bull. 2012, 57, 2802-2812. [CrossRef]

28. Fenta, A.A.; Yasuda, H.; Haregeweyn, N. The dynamics of urban expansion and land use/land cover changes using remote sensing and spatial metrics: The case of Mekelle city of northern Ethiopia. Int. J. Remote Sens. 2017, 38, 4107-4129. [CrossRef]

29. Zhao, M.; Cheng, W.; Zhou, C. Assessing spatiotemporal characteristics of urbanization dynamics in Southeast Asia using time series of DMSP/OLS nighttime light data. Remote Sens. 2018, 10, 47. [CrossRef]

30. Zhang, Q.; Seto, K.C. Can night-time light data identify typologies of urbanization? A global assessment of successes and failures. Remote Sens. 2013, 5, 3476-3494. [CrossRef]

31. Tan, K.C.; Lim, H.S.; Matjafri, M.; Abdullah, K. Landsat data to evaluate urban expansion and determine land use/land cover changes in Penang Island, Malaysia. Environ. Earth Sci. 2010, 60, 1509-1521. [CrossRef]

32. Yang, A.Y.; Wong, L.N.Y.; Chen, C.; Chen, T. Using multitemporal landsat imagery to monitor and model the influences of landscape pattern on urban expansion in a metropolitan region. J. Appl. Remote Sens. 2014, 8, 083639. [CrossRef]

33. Li, X.; Zhou, Y.; Asrar, G.R.; Meng, L. Characterizing spatiotemporal dynamics in phenology of urban ecosystems based on landsat data. Sci. Total Environ. 2017, 721, 605-606. [CrossRef]

34. Wahyudi, A.; Liu, Y.; Corcoran, J. Combining Landsat and landscape metrics to analyse large-scale urban land cover change: A case study in the Jakarta Metropolitan Area. Spat. Sci. 2018, 3, 1-20. [CrossRef]

35. Peng, W.; Wang, G.; Zhou, J.; Zhao, J.; Yang, C. Studies on the temporal and spatial variations of urban expansion in Chengdu, western China, from 1978 to 2010. Sustain. Cities Soc. 2015, 17, 141-150. [CrossRef]

36. Deng, X.; Huang, J.; Rozelle, S.; Uchida, E. Growth, population and industrialization, and urban land expansion of China. J. Urban. Econ. 2008, 63, 115. [CrossRef]

37. Zhang, L.L.; Yue, W.Z.; Fan, B.L. Measuring Urban Sprawl in Large Chinese Cities: A Case Study of Hangzhou. Sci. Geogr. Sin. 2014, 34, 394-400.

38. Mundia, C.N.; Aniya, M. Analysis of land use/cover changes and urban expansion of Nairobi city using remote sensing and GIS. Int. J. Remote Sens. 2005, 26, 2831-2849. [CrossRef]

39. Taubenböck, H.; Esch, T.; Felbier, A.; Wiesner, M.; Roth, S. Monitoring urbanization in mega cities from space. Remote Sens. Environ. 2012, 117, 162-176. [CrossRef]

40. Gong, P.; Li, X.C.; Zhang, W. 40-Year (1978-2017) human settlement changes in China reflected by impervious surfaces from satellite remote sensing. Sci. Bull. 2019, 11, 756-763. [CrossRef]

41. Herold, M.; Scepan, J.; Clarke, K.C. The use of remote sensing and landscape metrics to describe structures and changes in urban land uses. Environ. Plann. A 2002, 34, 1443-1458. [CrossRef]

42. Weng, Q.; Hua, L.; Lu, D. Assessing the effects of land use and land cover patterns on thermal conditions using landscape metrics in city of Indianapolis, United States. Urban. Ecosyst. 2007, 10, 203-219. [CrossRef]

43. Sinha, P.N.; Patel, N.; Jeyaseelan, A.T.; Singh, V.K. Quantification of urban landscape dynamics using patch parameters and landscape indices: An analytical study of Ranchi. J. Indian Soc. Remote Sens. 2011, 39, 225-233. [CrossRef]

44. Luck, M.; Wu, J.G. A gradient analysis of urban landscape pattern: A case study from the Phoenix metropolitan region, Arizona, USA. Landsc. Ecol. 2002, 17, 327-339. [CrossRef]

45. Cao, Y.; Bai, Z.; Zhou, W.; Ai, G. Gradient analysis of urban construction land expansion in the Chongqing urban area of China. J. Urban. Plan. D 2014, 141, 05014009. [CrossRef]

46. Batisani, N.; Yarnal, B. Urban expansion in Centre County, Pennsylvania: Spatial dynamics and landscape transformations. Appl. Geogr. 2009, 29, 235-249. [CrossRef]

47. Liu, H.; Weng, Q. Landscape metrics for analysing urbanization-induced land use and land cover changes. Geocarto Int. 2013, 28, 582-593. [CrossRef]

48. Han, R.D.; Zhang, L.; Zheng, Y.; Wang, H.; Zhang, J. Urban expansion and its ecological environmental effects in Bangkok, Thailand. Acta Ecol. Sin. 2017, 37, 6322-6334.

49. Shen, G.; Abdoul, N.I.; Zhu, Y.; Wang, Z.; Gong, J. Remote sensing of urban growth and landscape pattern changes in response to the expansion of Chongming Island in Shanghai, China. Geocarto Int. 2017, 32, 488-502. [CrossRef] 
50. Berling-Wolff, S.; Wu, J. Modeling urban landscape dynamics: A case study in Phoenix, USA. Urban. Ecosyst. 2004, 7, 215-240. [CrossRef]

51. Xie, Y.; Yu, M.; Bai, Y.; Xing, X. Ecological analysis of an emerging urban landscape pattern-desakota: A case study in Suzhou, China. Landsc. Ecol. 2006, 21, 1297-1309. [CrossRef]

52. Ji, W.; Ma, J.; Twibell, R.W.; Underhill, K. Characterizing urban sprawl using multi-stage remote sensing images and landscape metrics. Comput. Environ. Urban. 2006, 30, 861-879. [CrossRef]

53. Ghani, N.L.A.; Abidin, S.Z.Z. A modified landscape expansion index algorithm for urban growth classification using satellite remote sensing image. Adv. Sci. Lett. 2018, 24, 1843-1846. [CrossRef]

54. Benza, M.; Weeks, J.R.; Stow, D.A.; López-Carr, D.; Clarke, K.C. A pattern-based definition of urban context using remote sensing and GIS. Remote Sens. Environ. 2016, 183, 250-264. [CrossRef]

55. He, C.; Liu, Z.; Tian, J.; Ma, Q. Urban expansion dynamics and natural habitat loss in China: A multiscale landscape perspective. Global Change Biol. 2014, 20, 2886-2902. [CrossRef]

56. Yang, C.; Li, Q.; Zhong, H.; Chen, J.; Shi, T.; Ding, K.; Wu, G. Spatiotemporal evolution of urban agglomerations in four major bay areas of US, China and Japan from 1987 to 2017: Evidence from remote sensing images. Sci. Total Environ. 2019, 671, 232-247. [CrossRef]

57. Wang, Q. Reach on Chinese Urban Expansion Characteristic and Driving Factors in Recent 30 Years; Chinese Academy of Sciences: Beijing, China, 2007.

58. Tan, W.B.; Liu, B.; Zhang, Z.X.; Ling, W. Remote sensing monitoring and analyzing of the urban built-up land expansion in Kunming in 1974-2004. J. Geo-Info. Sci. 2009, 11, 117-124. [CrossRef]

59. Mu, J.X. Study on the Expansion of Construction Land in Xi'an. Mod. Urban. Res. 2007, 4, 38-42.

60. Li, A.M.; Liu, B.; Lv, A.M. Research on expansion of built-up area in Zhengzhou during 1999-2007 based on multi-original remote sensing images. J. Zhengzhou Univ. 2011, 32, 125-128.

61. Taubenböck, H.; Weigand, M.; Escha, T.; Staaba, J.; Wurma, M.; Masta, J.; Dechab, S. A new ranking of the world's largest cities—Do administrative units obscure morphological realities? Remote Sens. Environ. 2019, 232, 111353. [CrossRef]

62. Shimoni, M.; Lopez, J.; Forget, Y.; Wolff, E.; Michellier, C.; Grippa, T.; Linard, C.; Gilbert, M. An urban expansion model for African cities using fused multi temporal optical and SAR data. IEEE Geosci. Remote Symp. 2015, 1159-1162. [CrossRef]

63. Sun, Y.; Zhao, S. Spatiotemporal dynamics of urban expansion in 13 cities across the Jing-Jin-Ji urban agglomeration from 1978 to 2015. Ecol. Indic. 2018, 87, 302-313. [CrossRef]

64. Hai, M.P.; Yamaguchi, Y. Urban growth and change analysis using remote sensing and spatial metrics from 1975 to 2003 for Hanoi, Vietnam. Int. J. Remote Sens. 2011, 32, 1901-1915.

65. Simwanda, M.; Murayama, Y. Spatiotemporal patterns of urban land use change in the rapidly growing city of Lusaka, Zambia: Implications for sustainable urban development. Sustain. Cities Soc. 2018, 39, 262-274. [CrossRef]

66. Taubenböck, H.; Wiesner, M. The spatial network of megaregions-types of connectivity between cities based on settlement patterns derived from EO-data. Comput. Environ. Urban. Syst. 2015, 54, 165-180. [CrossRef]

67. Fragkias, M.; Seto, K.C. Evolving rank-size distributions of intra-metropolitan urban clusters in south China. Comput. Environ. Urban. Syst. 2009, 33, 189-199. [CrossRef]

68. Hu, Z.; Li, Q.; Zou, Q.; Zhang, Q.; Wu, G. A bilevel scale-sets model for hierarchical representation of large remote sensing images. IEEE Trans. Geosc. Remote Sens. 2016, 54, 7366-7377. [CrossRef]

69. Vapnik, V.N. The Nature of Statistical Learning Theory; Springer Verlag: New York, NY, USA, 1995.

70. Li, H.; Gu, H.; Han, Y.; Yang, J. Object-oriented classification of high-resolution remote sensing imagery based on an improved colour structure code and a support vector machine. Int. J. Remote Sens. 2010, 31, 1453-1470. [CrossRef]

71. Foody, G.M.; Mathur, A. A relative evaluation of multiclass image classification by support vector machines. IEEE Trans. Geosci. Remote Sens. 2004, 42, 1335-1343. [CrossRef]

72. Yu, S.; Sun, Z.; Guo, H.; Zhao, X.; Sun, L.; Wu, M. Monitoring and analyzing the spatial dynamics and patterns of megacities along the maritime Silk Road. J. Remote Sens. 2017, 21, 169-181.

73. Stehman, S.V. Selecting and interpreting measures of thematic classification accuracy. Remote Sens. Environ. 1997, 62, 77-89. [CrossRef] 
74. Ghimire, B.; Rogan, J.; Miller, J. Contextual land-cover classification: Incorporating spatial dependence in land-cover classification models using random forests and the Getis statistic. Remote Sens. Lett. 2010, 1, 45-54. [CrossRef]

75. Yang, C.; Wu, G.; Ding, K.; Shi, T.; Li, Q.; Wang, J. Improving land use/land cover classification by integrating pixel unmixing and decision tree methods. Remote Sens. 2017, 9, 1222. [CrossRef]

76. Foody, G.M. Status of land cover classification accuracy assessment. Remote Sens. Environ. 2002, 80, $185-201$. [CrossRef]

77. Zhang, J.; Zhou, Y.K.; Renqiang, L.I.; Zhou, Z.J.; Zhang, L.Q. Accuracy assessments and uncertainty analysis of spatially explicit modeling for land use/cover change and urbanization: A case in Beijing metropolitan area. Sci. China Earth Sci. 2010, 53, 173-180. [CrossRef]

78. Liu, S.; Wu, C.J.; Shen, H.Q. A GIS based model of urban land use growth in Beijing. Acta Geogr. Sin. 2000, 55, 407-416.

79. Wu, W.; Zhao, S.; Zhu, C.; Zhao, S.; Jiang, J. A comparative study of urban expansion in Beijing, Tianjin and Shijiazhuang over the past three decades. Landscape Urban. Plan. 2015, 134, 93-106. [CrossRef]

80. Forman, RTT. Land Mosaics: The Ecology of Landscapes and Regions; Cambridge University Press: Cambridge, UK, 1995.

81. Xu, C.; Liu, M.; Zhang, C. The spatialtemporal dynamics of rapid urban growth in the Nanjing metropolitan region of China. Landsc. Ecol. 2007, 22, 925-937. [CrossRef]

82. Liu, X.P.; Xia, L.; Chen, Y.M.; Tan, Z.; Li, S.; Ai, B. A new landscape index for quantifying urban expansion using multi-temporal remotely sensed data. Landscape Ecol. 2010, 25, 671-682. [CrossRef]

83. Li, C.; Li, J.; Wu, J. Quantifying the speed, growth modes, and landscape pattern changes of urbanization: A hierarchical patch dynamics approach. Landsc. Ecol. 2013, 28, 1875-1888. [CrossRef]

84. Riitters, K.H.; O’Neill, R.V.; Hunsaker, C.T.; Wickham, J.D.; Yankee, D.H.; Timmins, S.P.; Jones, K.B.; Jackson, B.L. A factor analysis of landscape pattern and structure metrics. Landsc. Ecol. 1995, 10, $23-39$. [CrossRef]

85. Wu, J.; Jenerette, G.D.; Buyantuyev, A.; Redman, C.L. Quantifying spatiotemporal patterns of urbanization: The case of the two fastest growing metropolitan regions in the United States. Ecol. Complex. 2011, 8, 1-8. [CrossRef]

86. McGarigal, K.; Marks, B.J. FRAGSTATS: Spatial Pattern Analysis Program for Quantifying Landscape Structure; USDA Forest Service: Washington, DC, USA, 1995.

87. McGarigal, K. Fragstats Help; University of Massachusetts: Amherst, MA, USA, 2015.

88. Taubenböck, H.; Wiesner, M.; Felbier, A.; Marconcini, M.; Esch, T.; Dech, S. New dimensions of urban landscapes: The spatio-temporal evolution from a polynuclei area to a mega-region based on remote sensing data. Appl. Geogr. 2014, 47, 137-153. [CrossRef]

89. Tan, M.; Li, X.; Lv, C. An analysis of driving forces of urban land expansion in China. Econ. Geogr. 2003, 23, 635-639.

90. Wang, L.; Zhu, J.; Xu, Y.; Wang, Z. Urban built-up area boundary extraction and spatial-temporal characteristics based on land surface temperature retrieval. Remote Sens. 2018, 10, 473. [CrossRef]

91. Mu, F.; Zhang, Z. A comparative study of urban expansion on Hong Kong and Macao special administrative region in the past three decades. Int. Workshop Earth Obs. Remote Sens. Appl. 2008, 1-6. [CrossRef]

92. Qiu, T.P. Study on Land Development and Utilization System of Hong Kong and its Inspiration to the Mainland; South China University of Technology: Guangzhou, China, 2013.

93. Li, L.I.; Chi, Y.B.; Wang, Z.Y.; Wang, A.; Zhou, H. The spatio-temporal dynamic characteristics in expansion of major cities in china in 30 years since the reform and opening-up. J. Nat. Resources 2009, 24, 1933-1943.

94. Zhang, J.; Wang, Y.; Wang, C.; Wang, R.; Li, F. Quantifying the emergy flow of an urban complex and the ecological services of a satellite town: A case study of Zengcheng, China. J. Clean. Prod. 2016, 163, 267-276. [CrossRef]

95. Wang, W.W.; Jin, J.W.; Xiao, Z.P.; Shi, T.T. Urban expansion and its driving forces based on remote sensed data and GIS: A case study of Hangzhou city from 1991 to 2008. Geogr. Res. 2009, 28, 685-695.

96. Ma, Y.; Xu, R. Remote sensing monitoring and driving force analysis of urban expansion in Guangzhou city, China. Habitat Int. 2010, 34, 228-235. [CrossRef]

97. Silva, P.; Li, L. Mapping urban expansion and exploring its driving forces in the city of Praia, Cape Verde, from 1969 to 2015. Sustainability 2017, 9, 1434. [CrossRef] 
98. Sun, C.; Wu, Z.F.; Lv, Z.Q.; Yao, N.; Wei, J. Quantifying different types of urban growth and the change dynamic in Guangzhou using multi-temporal remote sensing data. Int. J. Appl. Earth Obs. 2013, 21, 409-417. [CrossRef]

99. National Development and Reform Commission of China (NDRC). National New-type Urbanization Plan. Available online: http://www.gov.cn/zhengce/2014-03/16/content_2640075.htm (accessed on 16 March 2014).

100. Zhang, Z.X.; Wen, Q.; Liu, F.; Zhao, X.; Liu, B.; Xu, J.; Yi, L.; Hu, S.; Wang, X.; Zuo, L.; et al. Urban expansion in China and its effect on cultivated land before and after initiating reform and open policy. Sci. China 2016, 59, 1930-1945. [CrossRef]

101. Wu, J. Effects of changing scale on landscape pattern analysis: Scaling relations. Landsc. Ecol. 2004, 19, 125-138. [CrossRef]

102. Xu, M.; He, C.; Liu, Z.; Dou, Y. How did urban land expand in china between 1992 and 2015? A multi-scale landscape analysis. PLOS ONE 2016, 11, e0154839.

103. Collinge, S.K. Ecological consequences of habitat fragmentation: Implications for landscape architecture and planning. Landsc. Urban. Plan. 1996, 36, 59-77. [CrossRef]

104. Magle, S.B.; Theobald, D.M.; Crooks, K.R. A comparison of metrics predicting landscape connectivity for a highly interactive species along an urban gradient in Colorado, USA. Landsc. Ecol. 2009, 24, 267-280. [CrossRef]

105. Gobattoni, F.; Pelorosso, R.; Lauro, G.; Leone, A.; Monaco, R. A procedure for mathematical analysis of landscape evolution and equilibrium scenarios assessment. Landsc. Urban. Plan. 2011, 103, $289-302$. [CrossRef]

106. Tannier, C.; Foltete, J.C.; Girardet, X. Assessing the capacity of different urban forms to preserve the connectivity of ecological habitats. Landsc. Urban. Plan. 2012, 105, 128-139. [CrossRef]

107. Shoshany, M.; Goldshleger, N. Land-use and population density changes in Israel-1950 to 1990: Analysis of regional and local trends. Land Use Policy 2002, 19, 123-133. [CrossRef]

108. Tan, M.H.; Lv, C. Urban land expansion and farmland loss in China. J. Nat. Res. 2005, 20, 52-58.

109. Liu, J.X. On the Administration of Migrant Population in Shenzhen City and its Countermeasures; Central China Normal University: Wuhan, China, 2011.

110. Yu, Y.E.; Zhang, H.O.; Xue, Q.; Chun-shan, Z. Study on the relationship between construction land expansion and economic growth pattern in the Pearl River Delta. Geogr. Res. 2011, 30, 2259-2271.

111. Liu, X.; Wang, Y.; Li, Y.; Liu, F.; Shen, J.; Wang, J.; Xiao, R.; Wu, J. Changes in arable land in response to township urbanization in a Chinese low hilly region: Scale effects and spatial interactions. Appl. Geogr. 2017, 88, 24-37. [CrossRef]

112. Lin, Y.; Fan, J.F.; Wen, Q.; Liu, S.; Li, B. Primary exploration of ecological theories and technologies for delineation of ecological redline zones. Acta Ecol. Sin. 2016, 36, 1244-1252.

113. Lu, Z. Xinhua News Agency. Available online: http://www.gov.cn/xinwen/2017-02/08/content_5166338.htm (accessed on 8 February 2017). 